\title{
Palladium and Platinum Diphenoxide and Aryl Phenoxide Complexes with Amine Donors: Effect of Hydrogen Bonding on Structure and Properties
}

\author{
Paul L. Alsters, ${ }^{\dagger}$ Patrick J. Baesjou, ${ }^{\dagger}$ Maurits D. Janssen, ${ }^{\dagger}$ Huub Kooijman, ${ }^{\ddagger}$ \\ Anneke Sicherer-Roetman, ${ }^{\ddagger}$ Anthony L. Spek, ${ }^{\ddagger}$ and Gerard van Koten ${ }^{*}{ }^{\dagger}$ \\ Department of Metal-Mediated Synthesis, Debye Research Institute, and Department of Crystal \\ and Structural Chemistry, Bivoet Center for Biomolecular Research, University of Utrecht, Padualaan 8 , \\ $3584 \mathrm{CH}$ Utrecht, The Netherlands
}

Recelved June 19, 1992

\begin{abstract}
Several palladium and platinum phenoxides, $\left[\mathrm{Pd}(\mathrm{OPh})_{2} \mathrm{~L}_{2}\right]\left(\mathrm{L}_{2}=\text { tmeda (1), (pyrrolidine) }\right)_{2}(2)$, $(N$ methylpyrrolidine $\left.)_{2}(3)\right)$ and $\left.[\mathrm{M}(\mathrm{OPh})(\mathrm{NCN})]\left(\mathrm{NCN}=\mathrm{C}_{6} \mathrm{H}_{3}\left(\mathrm{CH}_{2} \mathrm{NMe}_{2}\right\}_{2}-2,6\right) ; \mathrm{M}=\mathrm{Pd}(5), \mathrm{Pt}(6)\right)$ have been synthesized and characterized with special emphasis on the role of both $\mathrm{N}-\mathrm{H} \ldots \mathrm{O}$ and $\mathrm{O}-\mathrm{H} \ldots \mathrm{O}$ hydrogen bonding in the resulting structures of these metal phenoxides. The $\left[\mathrm{Pd}(\mathrm{OPh})_{2} \mathrm{~L}_{2}\right](1-3)$ complexes were obtained from the reaction of $\mathrm{Pd}(\mathrm{OAc})_{2}$ with 2 equiv of sodium phenoxide in the presence of the neutral ligand. The terdentate $\mathrm{N}-\mathrm{C}-\mathrm{N}$-bound arylmetal complexes, $[\mathrm{M}(\mathrm{OPh})(\mathrm{NCN})], 5$ and 6 , were synthesized by reacting $\left.\left[\mathrm{M}\left(\mathrm{C}_{6} \mathrm{H}_{3} \mathrm{CH}_{2} \mathrm{NMe}_{2}\right\}_{2}-2,6\right)\left(\mathrm{H}_{2} \mathrm{O}\right)\right] \mathrm{BF}_{4}$ with sodium phenoxide. Both 2,5 , and 6 react with excess phenol to form the corresponding phenol adducts, 4, 7, and 8, respectively. The structures of the phenoxides 2 and 5 and the phenol adducts 4 and 7 were studied by X-ray diffraction methods to establish their stereochemistry as well as the nature and structural details of the hydrogen bonding in the phenol adducts. Crystals of trans-[Pd(OPh) ${ }_{2}$ (pyrrolidine) $\left.)_{2}\right]$ (2) are tetragonal with $a=b=18.6615$ (15) $\AA, c=10.7713(6)$ $\AA$, space group $I 44_{1} / a, Z=8$, and $R=0.026$ for 1774 reflections with $I \geq 2.5 \sigma(I)$; crystals of trans-[Pd$(\mathrm{OPh})_{2}$ (pyrrolidine $\left.)_{2}\right] \cdot \mathrm{HOPh}(4)$ are monoclinic with $a=6.4039$ (3) $\AA, b=15.497$ (1) $\AA, c=15.085$ (1) $\AA$, $\beta=99.832(4)^{\circ}$, space group $P 2_{1} / c, Z=2$, and $R=0.032$ for 2224 reflections with $I \geq 2.5 \sigma(I)$; crystals of $\left.\left[\mathrm{Pd}(\mathrm{OPh})\left(\mathrm{C}_{6} \mathrm{H}_{3} \mid \mathrm{CH}_{2} \mathrm{NMe}_{2}\right\}_{2}-2,6\right)\right](5)$ are monoclinic with $a=6.1490(2) \AA, b=12.0595(6) \AA, c=23.1829$ (10) $\AA, \beta=97.251(3)^{\circ}$, space group $P 2_{1} / c, Z=4$, and $R=0.0223$ for 3387 reflections with $I \geq 2.5 \sigma(I)$; and crystals of $\left[\mathrm{Pd}(\mathrm{OPh})\left(\mathrm{C}_{6} \mathrm{H}_{3}\left(\mathrm{CH}_{2} \mathrm{NMe}_{2}\right\}_{2}-2,6\right)\right] \cdot \mathrm{HOPh}(7)$ are monoclinic with $a=8.5400(5) \AA, b=12.0445$ (7) $\AA, c=22.4473$ (14) $A, \beta=100.779(5)^{\circ}$, space group $P 2_{1} / n, Z=4$, and $R=0.0428$ for 3081 reflections with $I \geq 2.5 \sigma(I)$. Palladium phenoxide 2 has a unique dimeric structure consisting of two trans-Pd$(\mathrm{OPh})_{2}$ (pyrrolidine) ${ }_{2}$ monomers being held together by four identical (pyrrolidine) $\mathrm{N}-\mathrm{H}$... O (phenoxide) hydrogen bonds $(\mathrm{N} \ldots \mathrm{O}=2.866(3) \AA$ ). The Pd atoms are in close proximity of each other, but the resulting Pd...Pd distance ( 3.0960 (3) $\AA$ ) points to some repulsion between the metal centers. In the corresponding phenol adduct, 4, the dimeric structure is broken down by interaction of two phenol molecules resulting in two (phenol) $\mathrm{O}-\mathrm{H}$...O(phenoxide) hydrogen bonds $(2.638$ (4) $\AA$ ). The structural features of the NCN-bound palladium phenoxides, 5 and 7 , reflect the effect of changing the trans ligand from phenoxide to aryl on the $\mathrm{Pd}$-phenoxide bonding. In 5 a very short (phenoxide) $\mathrm{C}-\mathrm{O}$ bond of 1.305 (3) $\AA$ is observed which lengthens to 1.330 (6) $A$ in the phenol adduct 7. The strong hydrogen bonding in 7 is indicated by the short (phenoxide) O...O (phenol) bond distance of 2.567 (6) $\AA$ (cf. 2.638 (4) $\AA$ in 4). These results have been used to synthesize new monodentate $\mathrm{N}-\mathrm{C}-\mathrm{N}$-metal catecholate complexes, $\left[\mathrm{M}\left(\mathrm{C}_{6} \mathrm{H}_{3}\left(\mathrm{CH}_{2} \mathrm{NMe}_{2}\right]_{2} \cdot 2,6\right)\right.$ $\left.\left(\mathrm{OC}_{6} \mathrm{H}_{4} \mathrm{OH}-2\right)\right](9(\mathrm{M}=\mathrm{Pd}), 10(\mathrm{M}=\mathrm{Pt}))$, which contain an intramolecular $\mathrm{O}-\mathrm{H}$... $\mathrm{O}$ hydrogen bond. ${ }^{1} \mathrm{H}$ NMR studies show that 2 is monomeric in solution. Exchange between coordinated phenoxide and associated phenol in 4 remains slow on the NMR time scale (up to $97^{\circ} \mathrm{C}$ ) but occurs on the laboratory time scale (experiments with pentadeuteriophenol). The arylpalladium phenoxide complex 7 undergoes fast exchange between phenoxide and associated phenol indicating the large trans effect of the aryl ligand (cf. long $\mathrm{Pd}-0$ bond in 5). This exchange is slow on the ${ }^{1} \mathrm{H}$ NMR time scale in the corresponding platinum complex 8. Similarly, intramolecular phenol/phenoxide exchange is fast on the ${ }^{1} \mathrm{H}$ NMR time scale in the Pd-catecholate 9 but slow in the $\mathrm{Pt}$-catecholate 10. Thermodynamic parameters for the association of phenol with the palladium diphenoxide complexes 2 and 3 have been determined by means of ${ }^{1} \mathrm{H}$ NMR spectroscopy.
\end{abstract}

\section{Introduction}

Recent work has shown that late transition metal alkoxides and phenoxides have a strong tendency to be associated with alcohols or phenols through hydrogen bonding. ${ }^{1}$ Such hydrogen bonding has been confirmed by several crystal structures of this class of compounds but more importantly also persists to a large extent in solution. In some cases hydrogen bonding is so important that only the products coordinated with phenols via hydrogen bonding can be isolated and the additional amount of phenol required for the hydrogen bonding ( 1 or sometimes even 2 equiv) is an essential part of the reaction stoichiometry; i.e., the reaction only goes to completion when this hydrogen bonding is taken into account. ${ }^{1 b, h}$

\footnotetext{
- To whom correspondence should be addressed.

${ }^{\dagger}$ Debye Research Institute.

${ }^{\dagger}$ Bijvoet Center for Biomolecular Research.
}

Hydrogen bonding has been pervasively studied in organic chemistry. ${ }^{2}$ Not only can it strongly effect solid-state and solution structures, but it sometimes also influences the (stereo)selectivity of reactions. For example, the stereoselectivity of the epoxidation of allylic alcohols with

(1) (a) Kegley, S. E.; Schaverien, C. J.; Freudenberger, J. H.; Bergman, R. G. J. Am. Chem. Soc. 1987, 109, 6563. (b) Di Bugno, C.; Pasquali, M.; Leoni, P.; Sabatino, P.; Braga, D. Inorg. Chem. 1989, 28, 1390 . (c) Osakada, K.; Kim, Y. J.; Yamamoto, A. J. Organomet. Chem. 1990, 382, 303. (d) Kim, Y. J.; Osakada, K.; Takenaka, A.; Yamamoto, A. J. Am. Chem. Soc. 1990, 112, 1096. (e) Osakada, K.; Kim, Y.-J.; Tanaka, M.; Ishiguro, S.-i.; Yamamoto, A. Inorg. Chem. 1991, 30, 197. (f) Osakada, K.; Ohshiro, K.; Yamamoto, A. Organometallics 1991, 10, 404. (g) Seliggon, A. L.; Cowan, R. L.; Trogler, W. C. Inorg. Chem. 1991, 30, 3371. (h) Koelle, U. Hong Wang, M.; Raabe, G. Organometallics 1991, 10, 2573.

(2) (a) Pimentel, G. C.; McClellan, A. L. The Hydrogen Bond; W. H. Freeman: San Francisco, CA, 1960. (b) Joesten, M. D.; Schaed, L. J. Hydrogen Bonding; Marcel Dekker: New York, 1974. (c) The Hydrogen Bond; Schuster, P., Zundel, G., Sandorfy, C., Eds.; North Holland: Amsterdam, 1976. 
meta-chloroperoxybenzoic acid ( $m$-CPBA), leading to either the threo- or erythro-epoxide, is thought to be influenced by hydrogen bonding of the allylic $\mathrm{OH}$ group to $m$-CPBA. ${ }^{3}$ Thus, hydrogen bonding can enforce a certain approach of a reagent toward a reactive center in a substrate molecule. It is interesting to extend this concept to organometallic chemistry.

Thus far, study of late transition metal alkoxides (and phenoxides) has focused on organometallic complexes which, apart from the alkoxide unit, contain such strong donors as alkyl or hydride ligands. Simple archetypal palladium diphenoxide complexes of the type $\mathrm{Pd}(\mathrm{OPh})_{2} \mathrm{~L}_{2}$ ( $\mathrm{L}=$ neutral ligand) have been much less studied. ${ }^{4}$ This is probably due to the common belief that a soft metal like palladium has a low affinity for hard oxygen donors like alkoxide or phenoxide. ${ }^{5}$ The kinetic lability of the late transition metal-oxygen bond ${ }^{6}$ makes such complexes potentially attractive as reagents or catalysts, and it would be interesting to extend the numerous stoichiometric and catalytic applications of palladium acetate to palladium bisphenoxide complexes. The higher basicity of a phenoxide group compared to an acetate ligand may result in additional or different chemistry, and it can be expected that much of this difference can be traced beck to the higher tendency for hydrogen bonding interactions of phenoxides compared to acetates. Recent advances in the development of $\mathrm{C}-\mathrm{O}$ coupling reactions ${ }^{7}$ merit further knowledge of the properties of such complexes in order to achieve the success that has already been established for $\mathrm{C}-\mathrm{C}$ coupling reactions with late transition metal catalysts. 8

In this paper, we report the synthesis, properties, and structure of several palladium and platinum phenoxides, with emphasis on the role of both $\mathrm{N}-\mathrm{H}$... $\mathrm{O}$ and $\mathrm{O}-\mathrm{H}$... $\mathrm{O}$ hydrogen bonding. Both palladium diphenoxides and arylpalladium and -platinum phenoxides with the monoanionic, terdentate, $\mathrm{N}-\mathrm{C}-\mathrm{N}$-bound ligand $\left[\mathrm{C}_{6} \mathrm{H}_{3}\right.$ $\left.\left.\left\{\mathrm{CH}_{2} \mathrm{NMe}_{2}\right\}_{2}-2,6\right)\right]^{-}$will be discussed. Thermodynamic parameters for the association of two palladium diphenoxides with phenol have been determined.

\section{Results and Discussion}

Preparation of the Complexes. Reaction of palladium acetate with 2 equiv of sodium phenoxide in the presence

(3) (a) Chamberlain, P.; Roberts, M. L.; Whitham, G. H. J. Chem. Soc. $B$ 1970, 1374. (b) Sharpless, K. B.; Verhoeven, T. R. Aldrichim. Acta $1979,12,63$.

(4) The complexes $\left[\mathrm{Pd}(\mathrm{OPh})_{2}\left(\mathrm{PPh}_{3}\right)_{2}\right]$ and $\left[\mathrm{Pt}(\mathrm{OPh})_{2}\left(\mathrm{PPh}_{3}\right)_{2}\right]$ have been prepared, but information about their properties is lacking. (a) Tayim, H. A.; Akl, N. S. J. Inorg. Nucl. Chem. 1974, 36, 944. (b) Berenblyum, A. S.; Lakhman, L. I.; Moiseev, I. I.; Radchenko, E. D. Koord. Khim. 1976, 2, 841. (c) Roffia, P.; Gregorio, G.; Conti, F.; Pregaglia, G. F.; Ugo, R. J. Mol. Catal. 1977, 2, 191.

(5) (a) Barnard, C. F. J.; Russell, M. J. H. Comprehensive Coordination Chemistry; Wilkinson, G., Ed.; Pergamon Press: Oxford, U.K., 1987

Vol. 6, p 1112. (b) Cotton, F. A.; Wilkinson, G. Advanced Inorganic Chemistry, 5th ed.; Wiley: New York, 1988; p 924.

(6) Bryndza, H. E.; Fong, L. K.; Paciello, R. A.; Tam, W.; Bercaw, J. E. J. Am. Chem. Soc. 1987, 109, 1444.

(7) (a) Bryndza, H. E.; Calabrese, J. C.; Wreford, S. S. Organometallics 1984, 3, 1603. (b) Bernard, K. A.; Atwood, J. D. Organometallics 1987 6, 1133. (c) Bernard, K. A.; Atwood, J. D. Organometallics 1988, 7, 235. (d) Bernard, K. A.; Atwood, J. D. Organometallics 1989, 8, 795. (e) Bernard, K. A.; Churchill, M. R.; Janik, T. S.; Atwood, J. D. Organometallics 1990,9, 12. (f) Thompson, J. S.; Bernard, K. A.; Rappoli, B J.; Atwood, J. D. Organometallics 1990, 9, 2727. (g) Glueck, D. S. Newman Winslow, L. J.; Bergman, R. G. Organometallics 1991, 10, 1462. (h) Thompson, J. S.; Randall, S. L.; Atwood J. D. Organometallics 1991 , 10, 3906. (i) Alsters, P. L.; Boersma, J.; van Koten, G. Tetrahedron Lett. $1991,32,675$.

(8) (a) Brown, J. M.; Cooley, N. A. Chem. Rev. 1988, 88, 1031. (b) Maryanoff, C. A.; Mills, J. E.; Stanzione, R. C.; Hortenstine, J. T. In Catalysis of Organic Reactions; Rylander, P. N., Greenfield, H., Augustine, R. L., Eds.; Marcel Dekker: New York, 1988; p 359. (c) Negishi, E.-i.; Takahashi, T.; Akiyoshi, K. In ref. 8 b, p 381 .

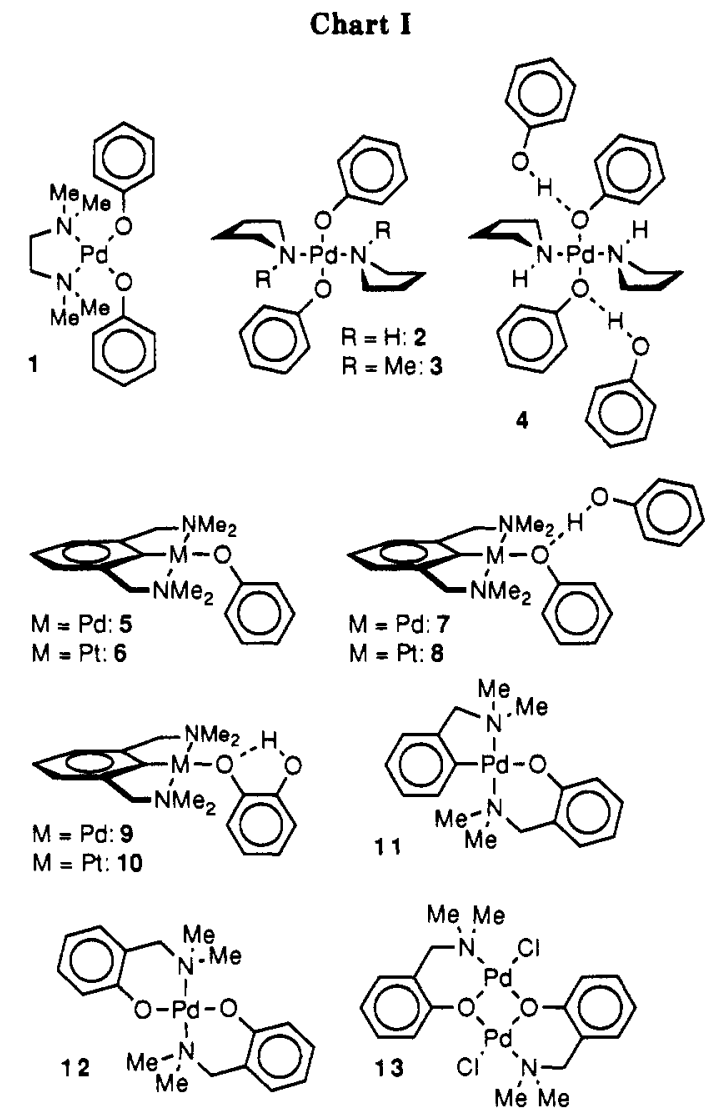

of neutral ligands such as tmeda (tmeda $=N, N, N^{\prime}, N^{\prime}$ tetramethylethane-1,2-diamine), pyrrolidine, or $N$. methylpyrrolidine affords the corresponding complexes $\left[\mathrm{Pd}(\mathrm{OPh})_{2} \mathrm{~L}_{2}\right](1-3$; see Chart I) as orange to orange-red solids. The tmeda complex 1 is thermally stable for months at room temperature, but the $N$-methylpyrrolidine complex 3 blackens within several days and must be stored at low temperature $\left(-30^{\circ} \mathrm{C}\right)$. The pyrrolidine complex 2 holds an intermediate position. Interestingly, single crystals of this compound blacken much more rapidly than amorphous powders of the complex that are stable for weeks at room temperature. Addition of 2 equiv of phenol to a dichloromethane solution of 2 and subsequent precipitation with pentane results in the formation of the bis(phenol) adduct 4 as a yellow-orange crystalline material. This compound is very stable and melts without decomposition at $122^{\circ} \mathrm{C}$. The terdentate $\mathrm{N}-\mathrm{C}-\mathrm{N}$-bound aryl complexes $\left[\mathrm{M}(\mathrm{OPh})\left(\mathrm{C}_{6} \mathrm{H}_{3}\left\{\mathrm{CH}_{2} \mathrm{NMe}_{2}\right\}_{2}-2,6\right)\right]$ ([M$(\mathrm{OPh})(\mathrm{NCN})] ; \mathrm{M}=\mathrm{Pd}(5), \mathrm{Pt}(6))$ are readily obtained from the reaction of the cationic aqua complexes [M$\left.\left(\mathrm{C}_{6} \mathrm{H}_{3}\left\{\mathrm{CH}_{2} \mathrm{NMe}_{2}\right\}_{2}-2,6\right)\left(\mathrm{H}_{2} \mathrm{O}\right)\right] \mathrm{BF}_{4}$ with sodium phenoxide as slightly yellow (5) or white (6) solids. Both are stable for months at room temperature. The arylpalladium and -platinum phenoxides 5 and 6 associate with phenol to give the adducts 7 and 8 , respectively. Like phenol adduct 4 , these adducts melt without decomposition at $160^{\circ} \mathrm{C}$. The phenoxide ligand of the complexes 5 and 6 is easily exchanged for a monodentate coordinated catecholate unit, affording 9 and 10, respectively. These exchange reactions go to completion in the presence of a stoichiometric amount of catechol.

Molecular Structures of $2,4,5$, and 7. In order to see whether the palladium diphenoxides have a cis or trans structure and to investigate the influence of hydrogen bonding in such complexes, an X-ray determination of 2, $\left.\left[\mathrm{Pd}(\mathrm{OPh})_{2} \text { (pyrrolidine }\right)_{2}\right]$, and $4,\left[\mathrm{Pd}(\mathrm{OPh})_{2}\right.$ (pyrrolidine $)_{2}$ ]-2HOPh, was carried out. Selected bond lengths and bond angles are summarized in Table I. Crystals of 
Table I. Selected Interatomic Distances $(\AA)$ and Angles (deg) for [Pd(OPh) $\left.{ }_{2}(\text { pyrrolidine })_{2}\right](2)$, $\left.\left.\left[\mathrm{Pd}(\mathrm{OPh})_{2} \text { (pyrrolidine }\right)_{2}\right] \cdot 2 \mathrm{HOPh}(4),\left[\mathrm{Pd}(\mathrm{OPh})\left(\mathrm{C}_{6} \mathrm{H}_{3} \mid \mathrm{CH}_{2} \mathrm{NMe}_{2}\right\}_{2}-2,6\right)\right](5)$, and $\left.\left[\mathrm{Pd}(\mathrm{OPh})\left(\mathrm{C}_{6} \mathrm{H}_{3} \mid \mathrm{CH}_{2} \mathrm{NMe}_{2}\right\}_{2}-2,6\right)\right] \bullet \mathrm{HOPh}(7)$

\begin{tabular}{|c|c|c|c|c|c|c|c|}
\hline \multicolumn{8}{|c|}{ Distances } \\
\hline \multicolumn{2}{|c|}{2} & \multicolumn{2}{|c|}{4} & \multicolumn{2}{|c|}{$\mathbf{5}$} & \multicolumn{2}{|c|}{7} \\
\hline $\begin{array}{l}\mathrm{Pd}-\mathrm{O} \\
\mathrm{Pd}-\mathrm{N} \\
\mathrm{C}(1)-\mathrm{O} \\
\mathrm{N}^{*} . . . \mathrm{O} \\
\mathrm{Pd} . . . \mathrm{Pd} *\end{array}$ & $\begin{array}{l}2.0031(19) \\
2.071(2) \\
1.335(3) \\
2.868(3) \\
3.0980(4)\end{array}$ & $\begin{array}{l}\mathrm{Pd}-\mathrm{O}(1) \\
\mathrm{Pd}-\mathrm{N} \\
\mathrm{C}(1)-\mathrm{O}(1) \\
\mathrm{C}(11)-\mathrm{O}(2) \\
\mathrm{O}(1) \ldots \mathrm{O}(2) \\
\mathrm{N} \ldots \mathrm{O}(2)^{*}\end{array}$ & $\begin{array}{l}2.018(2) \\
2.048(3) \\
1.351(4) \\
1.372(4) \\
2.638(4) \\
3.061(4)\end{array}$ & $\begin{array}{l}\mathrm{Pd}-\mathrm{O} \\
\mathrm{Pd}-\mathrm{C}(1) \\
\mathrm{Pd}-\mathrm{N}(1) \\
\mathrm{Pd}-\mathrm{N}(2) \\
\mathrm{C}(13)-\mathrm{O}\end{array}$ & $\begin{array}{l}2.1198(18) \\
1.910(2) \\
2.0987(17) \\
2.1022(19) \\
1.305(3)\end{array}$ & $\begin{array}{l}\mathrm{Pd}-\mathrm{O} \\
\mathrm{Pd}-\mathrm{C}(1) \\
\mathrm{Pd}-\mathrm{N}(1) \\
\mathrm{Pd}-\mathrm{N}(2) \\
\mathrm{C}(13)-\mathrm{O}(1) \\
\mathrm{C}(19)-\mathrm{O}(2) \\
\mathrm{O}(1) \ldots \mathrm{O}(2)\end{array}$ & $\begin{array}{l}2.139(4) \\
1.901(5) \\
2.103(4) \\
2.099(4) \\
1.330(6) \\
1.357(8) \\
2.567(6)\end{array}$ \\
\hline
\end{tabular}

Angles

\begin{tabular}{|c|c|c|c|c|c|c|c|}
\hline \multicolumn{2}{|c|}{2} & \multicolumn{2}{|c|}{4} & \multicolumn{2}{|c|}{5} & \multicolumn{2}{|c|}{7} \\
\hline $\begin{array}{l}\mathrm{O}-\mathrm{Pd}-\mathrm{N} \\
\mathrm{O}-\mathrm{Pd}-\mathrm{N}^{\prime} \\
\mathrm{O}-\mathrm{Pd}-\mathrm{O}^{\prime} \\
\mathrm{N}-\mathrm{Pd}-\mathrm{N}^{\prime} \\
\mathrm{Pd}-\mathrm{O}-\mathrm{C}(1)\end{array}$ & $\begin{array}{c}90.09(8) \\
89.54(8) \\
173.58(8) \\
173.44(9) \\
120.76(15)\end{array}$ & $\begin{array}{l}\mathrm{O}-\mathrm{Pd}-\mathrm{N} \\
\mathrm{O}-\mathrm{Pd}-\mathrm{N}^{\prime} \\
\mathrm{O}-\mathrm{Pd}-\mathrm{O}^{\prime} \\
\mathrm{N}-\mathrm{Pd}-\mathrm{N}^{\prime} \\
\mathrm{Pd}-\mathrm{O}-\mathrm{C}(1)\end{array}$ & $\begin{array}{c}86.89(10) \\
93.11(10) \\
180.0(5) \\
180.00(1) \\
119.72(19)\end{array}$ & $\begin{array}{l}\mathrm{O}-\mathrm{Pd}-\mathrm{N}(1) \\
\mathrm{O}-\mathrm{Pd}-\mathrm{N}(2) \\
\mathrm{C}(1)-\mathrm{Pd}-\mathrm{O} \\
\mathrm{N}(1)-\mathrm{Pd}-\mathrm{N}(2) \\
\mathrm{Pd}-\mathrm{O}-\mathrm{C}(13)\end{array}$ & $\begin{array}{c}97.82(7) \\
99.14(7) \\
176.34(8) \\
163.01(7) \\
125.05(16)\end{array}$ & $\begin{array}{l}\text { O-Pd-N(1) } \\
\text { O-Pd-N(2) } \\
\text { C(1)-Pd-O(1) } \\
\text { N(1)-Pd-N(2) } \\
\text { Pd-O-C(13) }\end{array}$ & $\begin{array}{r}100.13(15) \\
96.92(15) \\
172.96(18) \\
162.93(17) \\
128.1(3)\end{array}$ \\
\hline
\end{tabular}

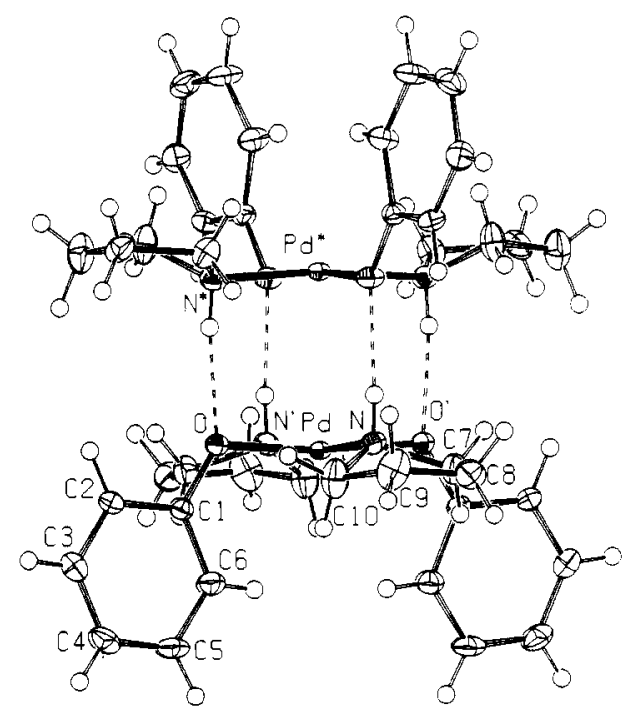

Figure 1. ORTEP drawing (50\% probability level) of the molecular structure of $\left.\left[\mathrm{Pd}(\mathrm{OPh})_{2} \text { (pyrrolidine }\right)_{2}\right](2)$ together with the adopted numbering scheme.

2 grow very easily upon slow distillation of diethyl ether into a $\mathrm{CH}_{2} \mathrm{Cl}_{2}$ solution of 2 . In the solid state, the compound has a unique dimeric structure, the two monomers being held together by four identical $\mathrm{N}-\mathrm{H}$... O hydrogen bonds (Figure 1). The compound has a trans square planar geometry. The Pd...Pd distance (3.0960 (3) $\AA$ ) is too long to indicate a significant interaction, but a slight disposition of the metal centers out of the square coordination plane can be clearly seen, and this indicates some repulsion between the metal centers (probably originating from an antibonding interaction between the two filled $\mathrm{d}_{z^{2}}$ orbitals). The N...O distance (2.868 (3) $\AA$ ) is typical for an ammonium $\mathrm{N}^{+}-\mathrm{H} \ldots \mathrm{O}$ hydrogen bond. ${ }^{9}$ The $\mathrm{Pd}-\mathrm{O}$ and $\mathrm{Pd}-\mathrm{N}$ bond lengths are comparable to those in cyclometalated $\mathrm{N}-\mathrm{O}$ palladium Schiff base complexes, which also adopt a trans geometry. ${ }^{10}$ The trans geometry is also found for $\left[\mathrm{Pd}(\mathrm{OAc})_{2}\left(\mathrm{Et}_{2} \mathrm{NH}\right)_{2}\right]^{11}$ and seems to be common for bis(amine)palladium complexes with two anionic oxy-

(9) Reference 2a, p 289.

(10) (a) Frasson, E.; Panattoni, C.; Sacconi, L. Acta Crystallogr. 1964, 17 477. (b) Braun, R. L.: Lingafelter, E. C. Acta Crystallogr. 1967, 22 787. (c) Jain, P. C.; Lingafelter, E. C. Acta Crystallogr. 1967, 23, 127. (d) Day, V. W.; Glick, M. D.; Hoard, J. L. J. Am. Chem. Soc. 1968, 90, 4803. (ii) Stephenson, T. A.; Morehouse, S. M.; Powell, A. R.; Heffer, J. P.; Wilkinson, G. J. Chem. Soc. 1965, 3632. gen donors (unless inhibited by N-N chelation, as for 1 ).

The crystal structure of 4 clearly reveals that the two $\mathrm{N}-\mathrm{H}$... $\mathrm{O}$ (phenoxide) hydrogen bonds in 2 have been replaced by two $\mathrm{O}-\mathrm{H}$-.. O(phenoxide) hydrogen bonds (Figure 2). The $0 . . .0$ distance of 2.638 (4) $\AA$ is typical for hydrogen bonding to late transition metal alkoxides or phenoxides. ${ }^{12}$ The compound has a trans square planar geometry around the palladium center. In the crystalline phase, the complex forms a one-dimensional polymeric chain held together by intermolecular $\mathrm{N}-\mathrm{H}$... $\mathrm{O}$ (phenol) hydrogen bonds. The N...O distance (3.061 (4) $\AA$ ) indicates that these hydrogen bonds are weak (cf. the $\mathrm{N}$... O value for 2). There are no important differences in $\mathrm{Pd}-\mathrm{O}$ and $\mathrm{Pd}-\mathrm{N}$ bond lengths and $\mathrm{Pd}-\mathrm{O}-\mathrm{C}$ bond angles between 2 and 4.

Since 5, $\left[\mathrm{Pd}(\mathrm{OPh})\left(\mathrm{C}_{6} \mathrm{H}_{3}\left\{\mathrm{CH}_{2} \mathrm{NMe}_{2}\right\}_{2}-2,6\right]\right.$, like 2 and 4, also has a phenoxo group that is flanked by two amine ligands, but with an aryl group instead of a phenoxide trans with respect to the phenoxo group, the crystal structure of 5 was determined in order to investigate the effect of changing the trans ligand (Figure 3 ). The bonding mode of the terdentate NCN ligand shows some features that are also found in other square planar complexes with this ligand, i.e. a small $N-M-N$ angle and a short $M-C(1)$ bond length, which both result from the small $\mathrm{N}-\mathrm{M}-\mathrm{C}(1)$ bite angle imposed by the chelate nature of the terdentate ligand system. ${ }^{13}$ The effect of this terdentate ligand system on the bond lengths and bond angles around the metal center can be clearly seen by comparison with the structure of the closely related complex [Pd$\left.\left(\mathrm{C}_{6} \mathrm{H}_{4} \mathrm{CH}_{2} \mathrm{NMe}_{2}-2\right)\left(\mathrm{OC}_{6} \mathrm{H}_{4} \mathrm{CH}_{2} \mathrm{NMe}_{2}-2\right)\right]$ (11). ${ }^{14}$ Bond distances and bond angles are quite similar, apart from the $\mathrm{Pd}-\mathrm{C}(1)$ distance, which is ca. $0.1 \AA$ shorter in $\mathbf{5}$ than in 11 , and the $\mathrm{N}(1)-\mathrm{Pd}-\mathrm{N}(2)$ angle, which is $14^{\circ}$ smaller in 5 compared to 11 . The Pd-O bond length in 5 is only slightly larger ( $\mathrm{Pd}-\mathrm{O}=2.0980(20)$ in 11) and is comparable with that in complexes where there is a methyl group in trans position with respect to the phenoxo group. ${ }^{10}$ The $\mathrm{C}-\mathrm{O}$ bond length within the phenoxide ligand of $\mathbf{5}$ is very short compared to this bond length in phenols (cf. $\mathrm{C}(13)-0$ in 5 with $\mathrm{C}(11)-\mathrm{O}(2)$ in 4). In fact, this $\mathrm{C}-\mathrm{O}$ bond length in 5 is only $0.02 \AA$ longer than the $\mathrm{C}-\mathrm{O}$ bond distance in a recently characterized planar $\eta^{6}$-bound oxocyclo-

(12) An overview of $0 \ldots O$ distances in hydrogen-bonded late transition metal species can be found in ref $1 \mathrm{~g}$.

(13) van Koten, G. Pure Appl. Chem. 1989, 61, 1681.

(14) Alsters, P. L.; Boersma, J.; Van Koten, G. To be submitted for publication. 

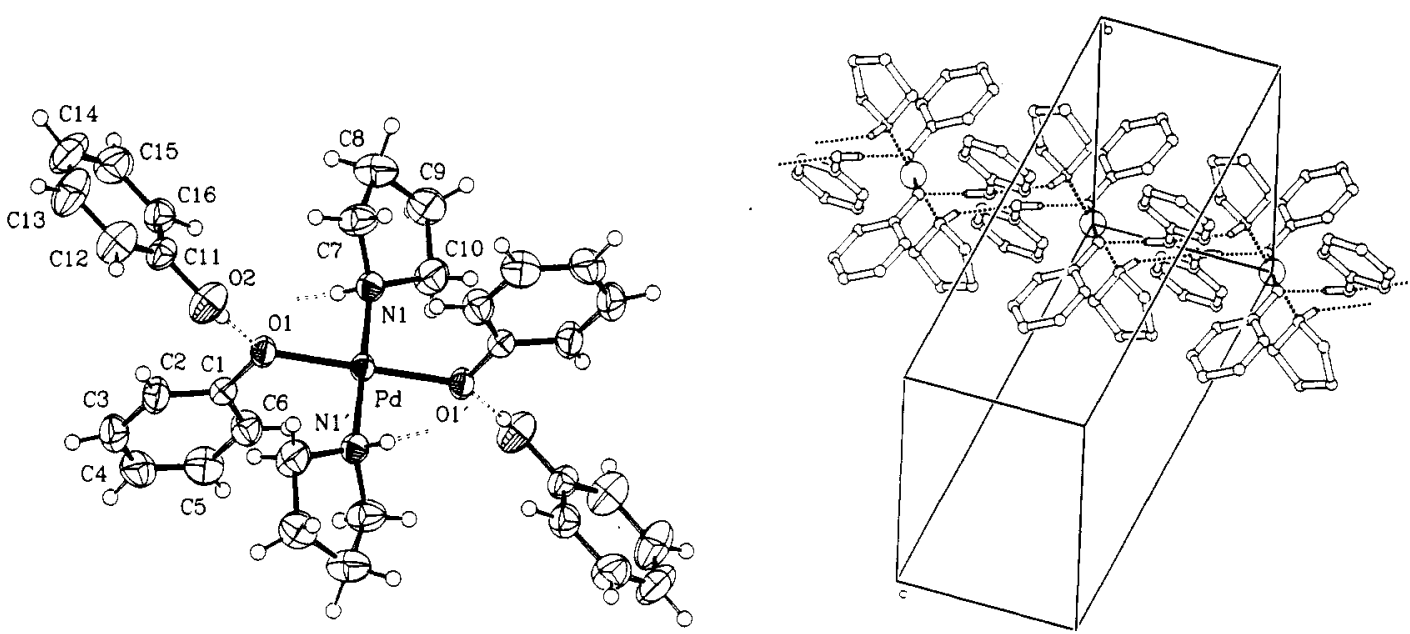

Figure 2. ORTEP drawing (50\% probability level) of the molecular structure of $\left[\mathrm{Pd}(\mathrm{OPh})_{2}(\text { pyrrolidine })_{2}\right]_{\cdot 2 \mathrm{HOPh}}(4)$ together with the adopted numbering scheme (left) and diagram of the crystal packing showing the one-dimensional polymeric chain held together by intermolecular $\mathrm{N}-\mathrm{H} . . . \mathrm{O}$ (phenol) hydrogen bonds (right).

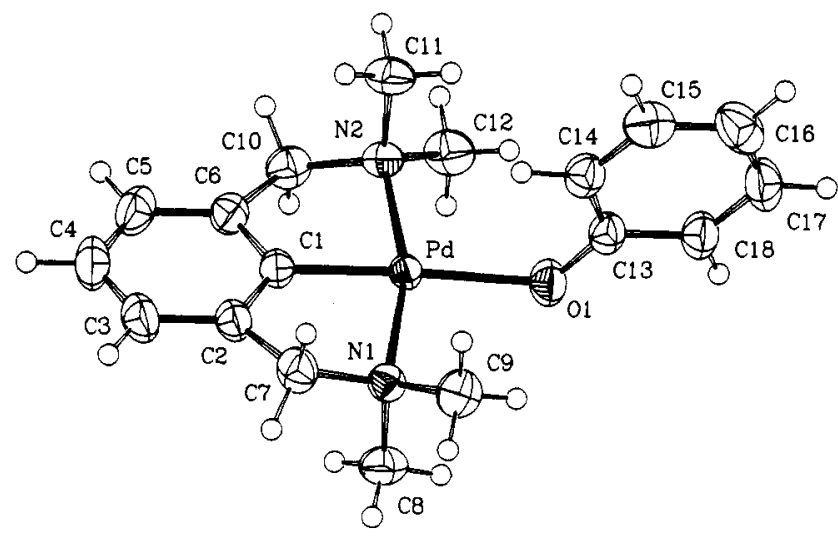

Figure 3. ORTEP drawing (50\% probability level) of the molecular structure of $\left[\mathrm{Pd}(\mathrm{OPh})\left(\mathrm{C}_{6} \mathrm{H}_{3}\left(\mathrm{CH}_{2} \mathrm{NMe}_{2}\right)_{2}-2,6\right)\right](5)$ together with the adopted numbering scheme.

hexadienylruthenium complex. ${ }^{\text {th }}$ A similar $\mathrm{C}-\mathrm{O}$ bond shortening, though less pronounced, is also observed for the related complex $11(\mathrm{C}-\mathrm{O}=1.321(3) \AA)^{14}$ and for 2.

Comparison of the crystal structures of 5 and 7, [Pd$\left.(\mathrm{OPh})\left(\mathrm{C}_{6} \mathrm{H}_{3} / \mathrm{CH}_{2} \mathrm{NMe}_{2}\right)_{2}-2,6\right] \cdot \mathrm{HOPh}$, provides information on the effect of hydrogen bonding in an otherwise similar ligand environment. The molecular structure of $\mathbf{7}$ is shown in Figure 4. The bonding of the NCN ligand is similar to that in 5 , the $\mathrm{Pd}-\mathrm{O}(1)$ bond is slightly longer (ca. 0.02 A) than the $\mathrm{Pd}-\mathrm{O}$ bond in 5 , and the $\mathrm{C}(13)-\mathrm{O}(1)$ bond length is somewhat less shortened (compared to the $\mathrm{C}-\mathrm{OH}$ bond length in phenols) than in 5 . It has been noted earlier that short $\mathrm{C}-\mathrm{O}$ bonds may be a characteristic feature of late transition metal alkoxides and phenoxides. ${ }^{15}$ The data in Table I indicate that this is not generally so; the C(1) $-O(1)$ bond length in 4 is only $0.02 \AA$ shorter than that in its associated phenol. The $O(1) \ldots O(2)$ bond distance in 7 is considerably shorter than in the bis(phenol) adduct of the diphenoxide 4. This $0 \cdots 0$ bond distance is one of the shortest known so far for hydrogen-bonded late transition metal alkoxide or phenoxide complexes and is indicative of a strong hydrogen bond (see below). ${ }^{12}$

IR and UV/Vis Spectra. The IR spectra (KBr disk) of the phenolates and hydrogen bonded phenol adducts show strong absorptions near $1280 \mathrm{~cm}^{-1}$ (Pd(OPh) 2 complexes) or at $1290-1320 \mathrm{~cm}^{-1}$ (phenoxides and catecholate with the NCN ligand). These absorptions as ascribed to

(15) Bryndza, H. E.; Tam, W. Chem. Rev. 1988, 88, 1163.

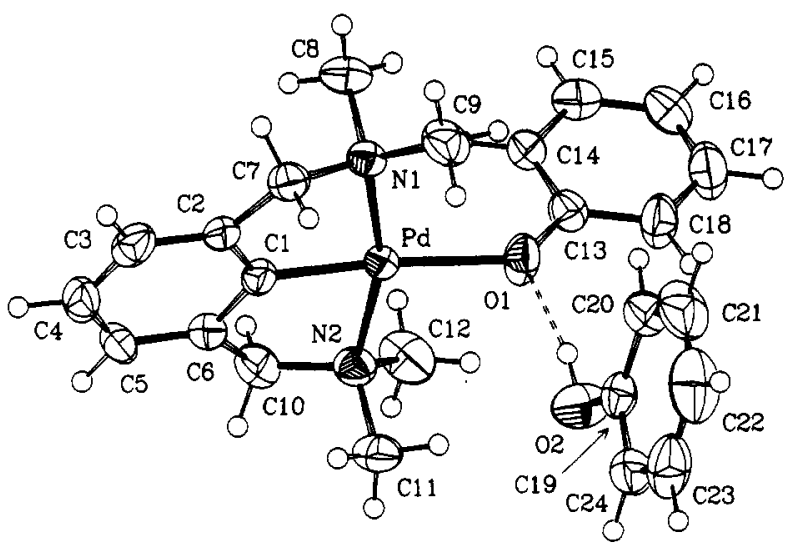

Figure 4. ORTEP drawing ( $50 \%$ probability level) of the molecular structure of $\left[\mathrm{Pd}(\mathrm{OPh})\left(\mathrm{C}_{6} \mathrm{H}_{3}\left\{\mathrm{CH}_{2} \mathrm{NMe}_{2}\right\}_{2}-2,6\right)\right] \cdot \mathrm{HOPh}(7)$ together with the adopted numbering scheme.

Table II. Absorptions in the C-O Stretching Region for Some Phenoxides (KBr Disk)

\begin{tabular}{clll}
\hline compd & \multicolumn{1}{c}{$\nu\left(\mathrm{cm}^{-1}\right)$} & compd & \multicolumn{1}{c}{$\nu\left(\mathrm{cm}^{-1}\right)$} \\
\hline $\mathbf{1}$ & 1280 & 9 & 1290,1270 \\
$\mathbf{2}$ & 1280 & 10 & $1310,1280,1250$ \\
$\mathbf{3}$ & 1280 & 11 & 1310 \\
$\mathbf{4}$ & 1260,1240 & 12 & 1280 \\
$\mathbf{5}$ & 1320 & 13 & 1240 \\
$\mathbf{6}$ & 1320,1310 & PhOH & 1240 \\
7 & $1310,1280,1260$ & PhONa & 1320 \\
$\mathbf{8}$ & $1290,1270,1250$ & &
\end{tabular}

the $\mathrm{C}-\mathrm{OM}$ stretching vibration of the phenolate unit and are summarized in Table II. C-O stretching frequencies ${ }^{14}$ of 11-13 as well as those observed for phenol and sodium phenoxide have been added for comparison.

The $\mathrm{C}-\mathrm{O}$ stretching frequencies of the palladium and platinum phenoxides are much higher than those observed for main group metal and early transition metal phenoxides $\left(\nu(\mathrm{C}-\mathrm{OM})\right.$ at $\left.1100-1200 \mathrm{~cm}^{-1}\right) .^{16}$ The higher frequency in the organometallic complexes than in the bis(phenoxo) complexes is consistent with the shorter $\mathrm{C}-\mathrm{O}$ bond in the crystal structure of 5 (and the related complex 11) than the $\mathrm{C}-\mathrm{O}$ bond lengths in 2 and 4 . The $\mathrm{C}-\mathrm{OM}$ stretching frequency of the organometallic phenoxides is very close to that of sodium phenoxide, whereas the lowest value is observed for the oxygen-bridged dimer 13. These

(16) Malhotra, K. C.; Martin, R. L. J. Organomet. Chem. 1982, 239, 


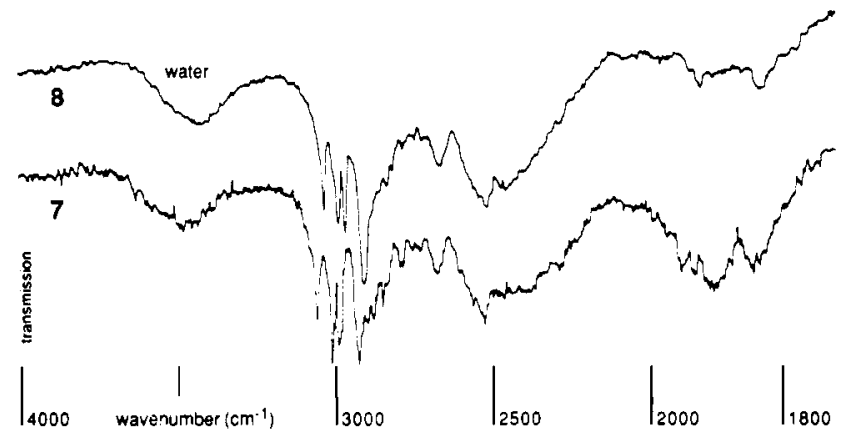

Figure 5. IR spectra (KBr disk) in the $1700-4000-\mathrm{cm}^{-1}$ region for the hydrogen-bonded phenol adducts $\left[\mathrm{Pd}(\mathrm{OPh})\left(\mathrm{C}_{6} \mathrm{H}_{3^{-}}\right.\right.$ $\left.\left.\left\{\mathrm{CH}_{2} \mathrm{NMe}_{2}\right\}_{2}-2,6\right)\right] \cdot \mathrm{HOPh}(7)$ and $\left[\mathrm{Pt}(\mathrm{OPh})\left(\mathrm{C}_{6} \mathrm{H}_{3}\left\{\mathrm{CH}_{2} \mathrm{NMe}_{2}\right\}_{2}^{-}\right.\right.$ $2,6)] \cdot H O P h(8)$.

facts indicate a higher degree of charge delocalization over the aromatic ring via resonance stabilization within the phenoxide ligand in complexes with a strong $\sigma$-donor (e.g. an aryl group) trans with respect to the phenoxide ligand, whereas bridging of the phenolate oxygen atom as in 13 lowers the degree of charge delocalization over the aromatic ring. The hydrogen-bonded adducts 4,7 , and 8 and the catecholates 9 and 10 show another absorption at $1240-1280 \mathrm{~cm}^{-1}$, which is ascribed to $\mathrm{C}-\mathrm{OH}$ stretching. For the complexes 7,8 , and 10 a third band is observed in this region, which makes an exact assignment of $\nu(\mathrm{C}-\mathrm{OH})$ for these compounds difficult.

The IR spectrum of 4 shows a broad $\nu(\mathrm{CO}-\mathrm{H})$ absorption at $2400-2700 \mathrm{~cm}^{-1}$, which is characteristic of a medium to strong hydrogen bond. ${ }^{2}$ For 7 and 8 , there are two very broad $\mathrm{O}-\mathrm{H}$ absorptions centered around 2500 and 1900 $\mathrm{cm}^{-1}$, respectively, of which the low-frequency band is particularly strong for the palladium complex (Figure 5). The occurrence of these two bands in these regions (both in the solid state and in solution) is indicative of a very strong hydrogen bond (well above $10 \mathrm{kcal} / \mathrm{mol}$ ). ${ }^{17}$ In particular, such patterns are also observed for adducts of phenols with their corresponding phenoxide anions. ${ }^{18}$ Thus, we conclude that the phenoxo ligand in 5 and 6 is exceptionally electron rich. Exceptionally strong hydrogen bonding has also been observed for a rhodium(I) phenoxide. ${ }^{1 \mathrm{a}}$ Strong hydrogen bonding in 7 and 8 is further corroborated by their ${ }^{1} \mathrm{H}$ NMR spectra (vide infra).

The palladium catecholate complex 9 shows a broad, intense $\nu(\mathrm{CO}-\mathrm{H})$ absorption around $2500 \mathrm{~cm}^{-1}$ in its IR spectrum. For the platinum catecholate, this absorption is found as a much weaker band at $3350 \mathrm{~cm}^{-1}$. The reason for the apparently weaker hydrogen bond in the solid state ( $\mathrm{KBr}$ disk) for the $\mathrm{Pt}$ catecholate compared to the $\mathrm{Pd}$ analogue is unclear. It may reflect different solid-state structures for these compounds, with a strong intermolecular $\mathrm{O}-\mathrm{H}$... O hydrogen bond for the $\mathrm{Pd}$ species and a weaker intramolecular hydrogen bond (as indicated by its structural formula 10) for the $\mathrm{Pt}$ catecholate. ${ }^{19}$ The relative weakness of the intramolecular hydrogen bond results from the bent nature of the $\mathrm{O}-\mathrm{H} \ldots \mathrm{O}$ system since the five-membered ring does not allow the $\mathrm{O}-\mathrm{H} \ldots \mathrm{O}$ unit

(17) Hadzi, D. Pure Appl. Chem. 1965, 11, 435

(18) Hadzi, D.; Novak, A.; Gordon, J. E. J. Phys. Chem. 1963, 67, 1118

(19) That the solid-state structures of 9 and 10 probably differ is not only indicated by the different values for $\nu(\mathrm{CO}-\mathrm{H})$ but also by other notable differences in their IR spectra, in particular in the finger-print region. In contrast, the IR spectra of 5 and 6 , as well as those of 7 and 8 , strongly resemble each other. We have recently obtained preliminary $X$-ray data of the platinum catecholate 10, which confirm the presence of intramolecular $\mathrm{O}-\mathrm{H} \ldots \mathrm{O}$ hydrogen bonding as indicated in the structural formula. Thus far, all attempts to crystallize its palladium analogue 9 have failed.
Table III. UV/Vis Data for 2 and $3\left(\mathrm{CH}_{2} \mathrm{Cl}_{2}\right.$ Solution)

\begin{tabular}{cl}
\hline compd & \multicolumn{1}{c}{$\lambda_{\max }(\mathrm{nm})\left(\epsilon\left(\mathrm{M}^{-1} \mathrm{~cm}^{-1}\right)\right)$} \\
\hline 2 & $330^{\circ}(3360), 294(9670), 254(30080)$ \\
3 & $342(3350), 297(8650), 257(31900)$
\end{tabular}

"Shoulder.

to adopt the preferred linear geometry ${ }^{2}$ (as observed in the crystal structures of 4 and 7 ).

The UV/vis spectra for complexes 2 and 3 (Table III) are similar and show an intense absorption around $\lambda=255$ $\mathrm{nm}$ originating from the aryl part within the phenoxide ligand and weaker bands from other chromophores around $\lambda=295 \mathrm{~nm}$ and at 330 (2; shoulder) or $342(3) \mathrm{nm}$.

${ }^{1}$ H NMR Spectra. The ${ }^{1} \mathrm{H}$ NMR spectra show wellresolved resonances of the ortho, meta, and para protons of the phenolate ligands. ${ }^{1} \mathrm{H}$ NMR data are presented in Table IV. The spectra are consistent with rapid rotation around the $\mathrm{C}-\mathrm{O}$ bond, which causes both ortho protons as well as both meta protons to be equivalent on the NMR time scale (at room temperature). The ortho protons ( $\delta$ $=7.1-7.5 \mathrm{ppm}$ ) are always substantially shifted to lower field compared to those of phenol and sodium phenolate, especially in the diphenoxides. We ascribe this low field shift of the ortho protons in the palladium and platinum phenoxides to the bent structure of the $\mathrm{M}-\mathrm{O}-\mathrm{Ph}$ unit (the $\mathrm{M}-\mathrm{O}-\mathrm{Ph}$ angle typically being about $120^{\circ}$, as observed in the crystal structures of $2,4,5$, and 7). Because of this bent structure, each ortho proton spends a considerable amount of time in a position where it is placed above the square coordination plane of the metal, and such a position is known to be characterized by low-field shifts as a result of the magnetic anisotropy of the metal center. ${ }^{20}$ Rapid rotation around the $\mathrm{M}-\mathrm{O}$ bond is indicated by the ${ }^{1} \mathrm{H}$ NMR spectra of the NCN complexes, both for the phenoxides and the catecholate. This is apparent from the equivalency of both protons of the $\mathrm{CH}_{2}$ groups and of both methyl groups within the $\mathrm{NMe}_{2}$ units. The platinum complexes 6, 8, and 10 show ${ }^{195} \mathrm{Pt}(I=1 / 2,33 \%$ abundance) satellites for the $\mathrm{CH}_{2} \mathrm{~N}$ and $\mathrm{NMe}_{2}$ signals $\left(J_{\mathrm{Pt}, \mathrm{H}}=48\right.$ and $38 \mathrm{~Hz}$, respectively), which are characteristic for this ligand and indicate rigid $\mathrm{N}$ donor coordination. ${ }^{21}$

The ${ }^{1} \mathrm{H}$ NMR spectrum of 2 shows a $\mathrm{N}-\mathrm{H}$ resonance at $2.8 \mathrm{ppm}$. The chemical shift is not dependent on concentration or temperature $\left(\mathrm{CDCl}_{3}\right.$ or toluene- $\left.d_{8}\right)$. Concentration and temperature dependence may be expected when $\mathrm{N}-\mathrm{H} \ldots \mathrm{O}$ hydrogen bonding persists in solution. In $\mathrm{CD}_{3} \mathrm{OD}$ solution this resonance is markedly shifted down field ( $\delta=3.9 \mathrm{ppm}$ ); this is a likely result of hydrogen bonding with the solvent. The absence of a low-field shift in $\mathrm{CDCl}_{3}$ or toluene- $d_{8}$ (pointing to the absence of $\mathrm{N}-\mathrm{H} \ldots \mathrm{O}$ hydrogen bonding) and the insensitivity of the $\mathrm{N}-\mathrm{H}$ chemical shift toward variation of temperature or concentration indicate that 2 is monomeric in solution. ${ }^{22}$

The bis(phenol) adduct 4 clearly shows two sets of resonances in the aromatic region for the coordinated phenol and the phenoxide ligand. No coalescence between the signals of the phenoxide ligand and (associated) phenol is observed in the ${ }^{1} \mathrm{H}$ NMR spectrum in a toluene- $d_{8}$ solution of 4 over the temperature range $25-97^{\circ} \mathrm{C}$, indicating that exchange between coordinated phenoxide and asso-

(20) (a) Miller, R. G.; Stauffer, R. D.; Fahey, D. R.; Parnell, D. R. J Am. Chem. Soc. 1970, 92, 1511. (b) Albinati, A.; Pregosin, P. S.; Wombacher, F. Inorg. Chem. 1990, 29, 1812.

(21) Terheijden, J.; van Koten, G.; Muller, F.; Grove, D. M.; Vrieze, K.; Nielsen, E.; Stam, C. H. J. Organomet. Chem. 1986, 315, 401.

(22) Cryoscopic determination of the molecular weight of 2 was hampered by its poor solubility in solvents with a high freezing point depression (e.g. benzene). 
Table IV. 'H NMR Data for Palladium and Platinum Phenoxides ${ }^{a}$

\begin{tabular}{|c|c|c|}
\hline compd & aryl & others \\
\hline 1 & $7.17(\mathrm{~d}, o-H), 6.98(\mathrm{t}, m-H), 6.46(\mathrm{t}, \mathrm{p}-H)$ & $2.61\left(\mathrm{~s}, \mathrm{NCH}_{3}\right), 2.56\left(\mathrm{~s}, \mathrm{NCH}_{2}\right)$ \\
\hline 2 & $7.41(\mathrm{~d}, 0-H), 7.15(\mathrm{t}, m-H), 6.59(\mathrm{t}, p-H)$ & $\begin{array}{l}3.13(\mathrm{~m}, \mathrm{NCH} H), 2.79(\mathrm{~m}, \\
\mathrm{NCH} H ; \mathrm{N} H), 1.65(\mathrm{~m}, \\
\left.\mathrm{CH}_{2} \mathrm{CH} H\right), 1.46(\mathrm{~m}, \mathrm{CH}, \mathrm{CH} H)\end{array}$ \\
\hline 3 & $7.41(\mathrm{~d}, o-H), 7.16(\mathrm{t}, m-H), 6.56(\mathrm{t}, p-H)$ & $\begin{array}{l}3.28(\mathrm{~m}, \mathrm{NCH} H), 2.50(\mathrm{~s}, \mathrm{NCH}) \\
2.21(\mathrm{~m}, \mathrm{NCH} H), 1.94(\mathrm{~m}, \\
\left.\mathrm{CH}_{2} \mathrm{CH} H\right), 1.76\left(\mathrm{~m}, \mathrm{CH}_{2} \mathrm{CH} H\right)\end{array}$ \\
\hline 4 & $\begin{array}{l}8.69(\mathrm{~s}, \mathrm{OH}), 7.48(\mathrm{~d}, o-H \mathrm{PdOPh}), 7.18(\mathrm{~m}, m-H \mathrm{PdOPh} ; m-H \mathrm{HOPh}), 6.99(\mathrm{~d}, o-H \mathrm{HOPh}) \\
\quad 6.86(\mathrm{t}, p-H \mathrm{HOPh}), 6.66(\mathrm{t}, p-H \mathrm{PdOPh})\end{array}$ & $\begin{array}{l}3.01(\mathrm{~m}, \mathrm{NCH} H), 2.73(\mathrm{~m}, \\
\mathrm{NCH} ; \mathrm{N} H), 1.55(\mathrm{~m}, \\
\left.\mathrm{CH}_{2} \mathrm{CH} H\right), 1.35\left(\mathrm{~m}, \mathrm{CH}_{2} \mathrm{CH} H\right)\end{array}$ \\
\hline $\mathbf{5}^{b}$ & $7.07(\mathrm{~m}, o-$ and $m-H \mathrm{PdOPh}), 6.96(\mathrm{dd}, p-H \mathrm{NCN}), 6.76(\mathrm{~d}, m-H \mathrm{NCN}), 6.40(\mathrm{tt}, p-H \mathrm{PdOPh})$ & $3.98\left(\mathrm{~s}, \mathrm{NCH}_{2}\right), 2.77\left(\mathrm{~s}, \mathrm{NCH}_{3}\right)$ \\
\hline $6^{b, c}$ & $7.12(\mathrm{~m}, o-$ and $m-H$ PtOPh), 6.96 (dd, $p-H$ NCN), 6.79 (d, $m-H$ NCN), 6.45 (tt, $p-H$ PtOPh) & $4.02\left(\mathrm{~s}, \mathrm{NCH}_{2}\right), 2.93\left(\mathrm{~s}, \mathrm{NCH}_{3}\right)$ \\
\hline $7^{b, d}$ & $\begin{array}{l}13.45(\mathrm{~s}, \mathrm{O} H), 7.19(\mathrm{bm}, o-\text { and } m-H \mathrm{PdOPh} ; o-\text { and } m-H \mathrm{HOPh}), 7.00(\mathrm{dd}, p-H \mathrm{NCN}), 6.80 \\
(\mathrm{~m}, m-H \mathrm{NCN} ; p-H \text { HOPh), } 6.60(\mathrm{bm}, p-H \mathrm{PdOPh})\end{array}$ & $4.00\left(\mathrm{~s}, \mathrm{NCH}_{2}\right), 2.78\left(\mathrm{~s}, \mathrm{NCH}_{3}\right)$ \\
\hline $8^{b, c}$ & $\begin{array}{l}11.89(\mathrm{~s}, 0 H), 7.30(\mathrm{~d}, o-H \mathrm{PtOPh}), 7.15(\mathrm{~m}, m-H \mathrm{PtOPh} ; o-\text { and } m-H \mathrm{OPh}), 6.99(\mathrm{dd}, p-H \\
\text { NCN), } 6.78(\mathrm{~m}, m-H \text { NCN; } p-H \text { HOPh), } 6.57(\mathrm{t}, p-H \text { PtOPh })\end{array}$ & $4.02\left(\mathrm{~s}, \mathrm{NCH}_{2}\right), 2.94\left(\mathrm{~s}, \mathrm{NCH}_{3}\right)$ \\
\hline $\mathbf{9}^{b, d}$ & $\begin{array}{l}7.26(\mathrm{~d}, H(1) \text { cat. }), 7.30(\mathrm{~s}, 0 H), 7.00(\mathrm{dd}, p-H \mathrm{NCN}), 6.81 \text { (m, } H(4) \text { cat.; } m-H \mathrm{NCN}), 6.68 \text { (t, } \\
H(2) \text { cat.) } 6.40(\mathrm{t}, H(3) \text { cat.) }\end{array}$ & $4.01\left(\mathrm{~s}, \mathrm{NCH} \mathrm{H}_{2}\right), 2.76\left(\mathrm{~s}, \mathrm{NCH}_{3}\right)$ \\
\hline $10^{b, c}$ & 7.30 (dd, $H(1)$ cat.), $7.25(\mathrm{~s}, \mathrm{OH}), 6.98$ (dd, $p-H \mathrm{NCN}), 6.82$ (m, $H(4)$ cat.; $m-H \mathrm{NCN}), 6.65$ & $4.03\left(\mathrm{~s}, \mathrm{NCH} H_{2}\right), 2.91\left(\mathrm{~s}, \mathrm{NCH}_{3}\right)$ \\
\hline
\end{tabular}

${ }^{a}$ All measurements in $\delta$ at $200 \mathrm{MHz}$ in $\mathrm{CDCl}_{3}$ at room temperature (unless denoted otherwise). Abbreviations: $\mathrm{NCN}^{-} \mathrm{C}_{6} \mathrm{H}_{3}$. $\left\{\mathrm{CH}_{2} \mathrm{NMe}_{2}\right\}_{2}-2,6$; cat. = monoanionic catecholate ligand; $\mathrm{OC}_{6} \mathrm{H}_{4} \mathrm{OH}-2$ (hydrogen ortho with respect to the anionic oxygen atom is numbered 1). Coupling constants within phenoxide and catecholate units: ${ }^{3} J=7-8 \mathrm{~Hz} ;{ }^{4} J=1.5 \mathrm{~Hz}$ (if visible). ${ }^{b}$ For NCN ligand: dd of $p-H, J=8$ $\mathrm{Hz}$ and $J=7 \mathrm{~Hz}$; d of $m-H, J=8 \mathrm{~Hz}$. ${ }^{c}$ For $\mathrm{NCH}_{2}:{ }^{3} J(\mathrm{Pt}, \mathrm{H})=48 \mathrm{~Hz}$. For $\mathrm{NCH}_{3}:{ }^{3} J(\mathrm{Pt}, \mathrm{H})=38 \mathrm{~Hz}$. ${ }^{d} \mathrm{At}-30^{\circ} \mathrm{C}$.

ciated phenol remains slow on the ${ }^{1} \mathrm{H}$ NMR time scale, even at high temperature (eq 1). However, addition of
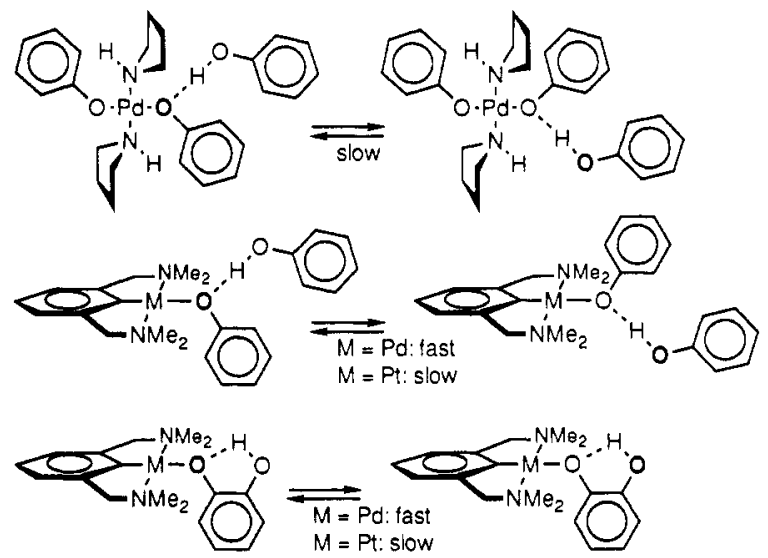

2 equiv of pentadeuteriophenol $\left(\mathrm{C}_{6} \mathrm{D}_{5} \mathrm{OH} / \mathrm{D}\right.$; partially deuterated at oxygen) to a $\mathrm{CDCl}_{3}$ solution of 2 results in the appearance of resonances of (associated) phenol and reduction of the phenoxide signals to half their original intensity. Therefore, although phenoxide/phenol exchange is slow on the NMR time scale, it occurs rapidly on the laboratory time scale. At room temperature, the $\mathrm{OH}$ signal is visible at ca. $8.7 \mathrm{ppm}$, which is at considerably lower field than the $\mathrm{OH}$ resonance at ca. $5.5 \mathrm{ppm}$ for noncomplexed phenol. Upon heating of a toluene- $d_{8}$ solution of 4 , the $\mathrm{OH}$ signal shifts to higher field $\left(\delta=5.6 \mathrm{ppm}\right.$ at $\left.97^{\circ} \mathrm{C}\right)$, consistent with a shift of the complexation equilibrium towards uncomplexed 2 and free phenol (vide infra).

In contrast to the bis(phenoxide) complex 4 , the ${ }^{1} \mathrm{H}$ NMR spectra of the arylpalladium phenoxide 7 indicate a fast exchange between the phenoxide and the associated phenol at room temperature (eq 2). This has also been found recently for phosphine palladium phenoxides with a methyl group trans with respect to the phenoxide ligand, and kinetic measurements indicate a simple intramolecular exchange mechanism. .d $^{\text {Id }}$ Coalescence of the resonances of the para protons of the associated phenol and the phenoxo group occurs at $-15^{\circ} \mathrm{C}$. The free energy of activation $\left(\Delta G^{*}\right.$ $\approx 12.7 \mathrm{kcal} / \mathrm{mol}$ ) is somewhat lower than that of the phosphine complexes (ca. $14.6 \mathrm{kcal} / \mathrm{mol}$ ). The much more facile exchange for 7 compared to 4 is almost certainly a result of the strong trans influence of an aryl group compared to a phenoxo group (as indicated by the longer $\mathrm{Pd}-\mathrm{O}$ bond length in 5 compared to that in 2). The $\mathrm{OH}$ signal in 7 is visible at very low field, ranging from $13.9 \mathrm{ppm}$ at $-60^{\circ} \mathrm{C}$ to $10.5 \mathrm{ppm}$ at $60^{\circ} \mathrm{C}$ (at $24^{\circ} \mathrm{C}$ it is at $11.9 \mathrm{ppm}$ ). These values are indicative of strong $\mathrm{O}-\mathrm{H}$... $\mathrm{O}$ hydrogen bonding.

Strong hydrogen bonding is also inferred from the ${ }^{1} \mathrm{H}$ NMR of the platinum complex 8, and the chemical shift of the $\mathrm{OH}$ signal varies from $11.9 \mathrm{ppm}\left(24^{\circ} \mathrm{C}\right)$ to $10.5 \mathrm{ppm}$ $\left(60^{\circ} \mathrm{C}\right)$; i.e. the $\mathrm{O}-\mathrm{H}$ chemical shift has a temperature dependence similar to that found for the Pd analogue 7. However, in contrast to 7 , exchange between associated phenol and the Pt-OPh unit is slow on the NMR time scale, even at $60^{\circ} \mathrm{C}$. As for the palladium diphenoxide complex 2, addition of 1 equiv of pentadeuteriophenol confirmed that phenol/phenoxide exchange occurs readily on the laboratory time scale.

The greater inertness of platinum phenoxides in phe$\mathrm{nol} /$ phenoxide exchange reactions compared to that of the corresponding palladium phenoxides is also revealed by the catecholate complexes 9 and 10 . The platinum catecholate 10 shows a well-defined first-order pattern for the four aromatic protons of the catecholate ligand. Three catecholate protons are found at $6.4-6.8 \mathrm{ppm}$ ), while a low-field doublet of doublets $(\delta=7.29 \mathrm{ppm})$ is ascribed to one of the ortho protons. The low-field shift of the ortho proton indicates that this proton is positioned (part of the time) above the square coordination plane around $\mathrm{Pt}$. The $\mathrm{OH}$ resonance $(7.25 \mathrm{ppm}$ ) is far less shifted to low field than in 8 . This indicates a rather weak hydrogen bond, which is likely a result of the bent nature of the $\mathrm{O}-\mathrm{H} \ldots \mathrm{O}$ system (see discussion of IR spectra). ${ }^{2}$ However, intramolecular hydrogen bonding in $\mathbf{1 0}$ is strong enough to drive the substitution of phenolate for catecholate to completion during its preparation, without the need for an excess of catechol. The low-field shift of one of the ortho protons in the ${ }^{1} \mathrm{H}$ NMR spectrum and the occurrence of the $\mathrm{OH}$ resonance at a position that is typical for a weak hydrogen bond (both in the IR and in the ${ }^{1} \mathrm{H}$ NMR spectrum) are in agreement with the structural formula given for 10 . In our point of view, these observations rule out two other possible bonding modes (in solution) of the catecholate ligand, as indicated in II and $\mathrm{III}^{23}$ in Chart II. 
Table V. ${ }^{13}$ C NMR Data for Palladium and Platinum Phenoxides ${ }^{a}$

\begin{tabular}{|c|c|c|}
\hline compd & aryl & others \\
\hline 1 & $168.24($ ipso-C), $128.0(m-C), 119.58(o-C), 114.21(p-C)$ & $61.88\left(\mathrm{NCH}_{2}\right), 49.91\left(\mathrm{NCH}_{3}\right)$ \\
\hline 2 & $167.04($ ipso-C), $129.36(m-C), 118.94(o-C), 115.16(p-C)$ & $\left.\mathrm{NCH}_{2}\right), 23.61\left(\mathrm{NCH}_{2} \mathrm{Cl}\right.$ \\
\hline 3 & 167.13 (ipso-C), $129.27(m-C), 118.69(o-C), 114.41(p-C)$ & $60.30\left(\mathrm{NCH}_{2}\right), 48.39\left(\mathrm{NCH}_{3}\right)$ \\
\hline 4 & $\begin{array}{l}165.18 \text { (ipso-C PdOPh), } 156.89(\text { ipso- } C \mathrm{HOPh}), 129.70 / 129.61(m-C \mathrm{PdOPh} \\
m-C \mathrm{HOPh}), 119.94(p-C \mathrm{HOPh}), 119.09(o-C \mathrm{PdOPh}), 116.49(p-C \mathrm{PdOPh}) \\
115.80(0-C \mathrm{HOPh})\end{array}$ & $50.46\left(\mathrm{NCH}_{2}\right), 23.52\left(\mathrm{NCH}_{2} \mathrm{Cl}\right.$ \\
\hline $\mathbf{5}$ & $\begin{array}{l}\text { 170.00 (ipso-C PdOPh), } 155.70 \text { (ipso-C NCN), } 145.06 \text { (o-C NCN), } 129.04(m-C \\
\text { PdOPh), } 124.07(p-C \text { NCN), 119.54/118.93 (m-C NCN; o-C PdOPh), } 112.01 \\
\text { (p-C PdOPh) }\end{array}$ & $74.40\left(\mathrm{NCH}_{2}\right), 52.29\left(\mathrm{NCH}_{3}\right)$ \\
\hline $6^{b}$ & $\begin{array}{l}\text { 170.05 (ipso-C PtOPh), } 144.03(o-C \mathrm{NCN}), 143.24(\text { ipso-C NCN), } 128.97(m-C \\
\text { PtOPh), } 122.92(p-C \text { NCN), } 119.12(m-C \mathrm{NCN} ; 0-C \mathrm{PtOPh}), 112.74(p-C \\
\text { PtOPh) }\end{array}$ & $77.69\left(\mathrm{NCH}_{2}\right), 53.98\left(\mathrm{NCH}_{3}\right)$ \\
\hline $7^{c}$ & $\begin{array}{l}\text { 165.86 (ipso-C PdOPh), } 158.28 \text { (ipso-C HOPh), } 155.37 \text { (ipso-C NCN), } 145.17 \\
\text { (o-C NCN), 129.88 (m-C PdOPh; } m-C \text { HOPh), } 124.73 \text { (p-C NCN), } 120.32 \\
\text { (m-C NCN; o-C PdOPh), 118.64 (p-C HOPh), } 116.04 \text { (o-C HOPh), } 114.52 \\
(p-C \text { PdOPh) }\end{array}$ & $74.07\left(\mathrm{NCH}_{2}\right), 52.73\left(\mathrm{NCH}_{3}\right)$ \\
\hline $8^{b}$ & $\begin{array}{l}167.73 \text { (ipso-C PtOPh), } 157.99 \text { (ipso-C HOPh), } 143.87(o-C \text { NCN), } 141.81 \\
\text { (ipso-C NCN), 129.42/129.13 (m-C PtOPh; } m-C \text { HOPh), } 123.24(p-C \text { NCN), } \\
119.27 \text { ( } m-C \text { NCN), 118.94 (o-C PtOPh), } 118.85(p-C \text { HOPh), } 115.99(o-C \\
\text { HOPh), } 114.40(p-C \text { PtOPh) }\end{array}$ & $77.27\left(\mathrm{NCH}_{2}\right), 53.91\left(\mathrm{NCH}_{3}\right)$ \\
\hline $\mathbf{9}^{d}$ & $\begin{array}{l}156.57(C(1) \text { cat.), } 155.72 \text { (ipso-C NCN), } 148.89(C(2) \text { cat. }), 145.23 \text { (o-C NCN), } \\
124.45 \text { ( } p-C \text { NCN), } 120.09 \text { ( } m-C \text { NCN), } 119.85 / 115.14 / 112.56 / 111.13 \text { (cat.) }\end{array}$ & $74.36\left(\mathrm{NCH}_{2}\right), 52.51\left(\mathrm{NCH}_{3}\right)$ \\
\hline $10^{b}$ & $\begin{array}{l}156.69(C(1) \text { cat.), } 149.23(C(2) \text { cat. }), 143.91(o-C \mathrm{NCN}), 142.10(\text { ipso-C NCN), } \\
123.17(p-C \mathrm{NCN}), 119.36 \text { (cat.), } 119.22(m-C \mathrm{NCN}), 115.12 / 113.34 / 111.35 \\
\text { (cat.) }\end{array}$ & $77.40\left(\mathrm{NCH}_{2}\right), 53.83\left(\mathrm{NCH}_{3}\right)$ \\
\hline
\end{tabular}

${ }^{a}$ All measurements in $\delta$ at $50 \mathrm{MHz}$ in $\mathrm{CDCl}_{3}$ or $\mathrm{CD}_{2} \mathrm{Cl}_{2}$ (for 1) at room temperature (unless denoted otherwise). Abbreviations: $\mathrm{NCN}=$ $\left.\mathrm{C}_{6} \mathrm{H}_{3} / \mathrm{CH}_{2} \mathrm{NMe}_{2}\right\}_{2}-2,6$; cat = monoanionic catecholate ligand; $\mathrm{OC}_{6} \mathrm{H}_{4} \mathrm{OH}-2$ (carbons bearing the anionic $\mathrm{O}$ and the $\mathrm{OH}$ group are numbered 1 and 2, respectively). ${ }^{b}$ For NCN ligand: ${ }^{3} J(\mathrm{Pt}, \mathrm{C}($ ortho $))=37 \mathrm{~Hz} ;{ }^{4} J(\mathrm{Pt}, \mathrm{C}($ meta $))=17 \mathrm{~Hz} ;{ }^{2} J\left(\mathrm{Pt}, \mathrm{C}\left(\mathrm{NCH}_{2}\right)\right)=31 \mathrm{~Hz} ;{ }^{2} J(\mathrm{Pt}, \mathrm{C}(\mathrm{NCH}))=9 \mathrm{~Hz}$; $\mathrm{Pt}, \mathrm{C}$ coupling on the ipso and para carbons of the NCN ligand not observed. ${ }^{\circ} \mathrm{At}-50^{\circ} \mathrm{C} .{ }^{d} \mathrm{At}-30^{\circ} \mathrm{C}$.

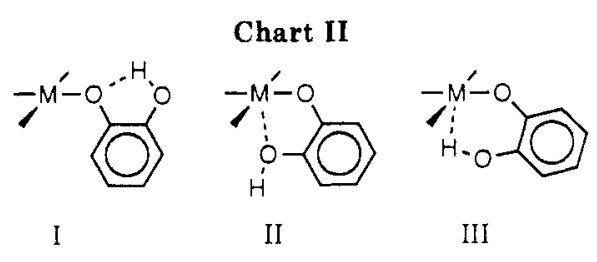

Neither of these alternatives explain the low-field shift of an ortho proton, and III would probably give rise to an extreme low-field resonance of the phenolic proton, which probably would show coupling with the platinum center. ${ }^{24}$ As four different signals are observed for the catecholate aromatic protons, there is apparently no intramolecular interconversion between the phenolic $\mathrm{OH}$ oxygen atom and the phenolate oxygen atom; i.e., phenol/phenoxide exchange is slow in 10, as it also is for 8. Rapid interconversion would result in the observation of only two aromatic resonances stemming from the catecholate ligand (eq 3). This is indeed observed for the palladium catecholate 9, whose ${ }^{1} \mathrm{H}$ NMR spectrum indicates rapid phenol/phenoxide exchange at room temperature as revealed by the presence of two broad resonances (each integrating for two protons) stemming from the catecholate ligand. At $-30^{\circ} \mathrm{C}$, four different signals of the catecholate unit are observed, and the spectrum strongly resembles that of its platinum analogue 10 in the aromatic region. Coalescence of the two triplets stemming from the protons para with respect to the $\mathrm{Pd}-\mathrm{O}$ and $\mathrm{H}-\mathrm{O}$ groups occurs at $5^{\circ} \mathrm{C}\left(\Delta G^{*}\right.$ $\approx 13.5 \mathrm{kcal} / \mathrm{mol}$ ).

${ }^{13} \mathrm{C}$ NMR Spectra. ${ }^{13} \mathrm{C}$ NMR data are collected in Table V. The chemical shifts for the phenoxide carbons in the non-hydrogen-bonded complexes $1-3,5$, and 6 are

(23) There is increasing evidence that transition metal centers can act as hydrogen bond acceptors, as shown in III. For a comprehensive article, see: Brammer, L.; Charnock, J. M.; Goggin, P. L.; Goodfellow, R. J.; Orpen, A. G.; Koetzle, T. F. J. Chem. Soc., Dalton Trans. 1991, 1789

(24) Wehman-Ooyevaar, I. C. M.; Grove, D. M.; van der Sluis, P.; Spek, A. L.; van Koten, G. J. Chem. Soc., Chem. Commun. 1990, 1367. very similar to those in typical anionic phenoxides like $\mathrm{PhO}^{-} \mathrm{Na}^{+}, \mathrm{PhO}^{-} \mathrm{NBu}_{4}^{+}$, or $\mathrm{PhO}^{-}\left(\mathrm{Et}_{2} \mathrm{~N}_{3} \mathrm{~S}^{+}{ }^{25}\right.$ Most informative are the low-field shift (by 12-15 ppm) of the ipso carbon atom ( $\delta=167-170 \mathrm{ppm}$ ) and the high-field shift (by 6-9 ppm) of the para carbon atom ( $\delta=115-112 \mathrm{ppm}$ ) compared to the corresponding shift values for phenol. ${ }^{26}$ The NCN-containing complexes show larger shifts than the diphenoxide complexes. These strong shifts indicate a high polarity of the $\mathrm{M}-\mathrm{O}$ bond $(\mathrm{M}=\mathrm{Pd}, \mathrm{Pt})$, and a similar conclusion based on ${ }^{13} \mathrm{C} N \mathrm{NMR}$ data has been drawn for $\mathrm{Pd}(\mathrm{I})$ phenoxides. ${ }^{25 \mathrm{a}}$ The larger shifts for the NCN complexes is in agreement with the trend toward shorter $\mathrm{C}-\mathrm{O}$ bonds in the organometallic phenoxides than in the diphenoxo complexes, as concluded above from the crystal structures and the IR spectra. The hydrogen-bonded bis(phenol) adduct 4 shows two sets of signals for the associated phenol and the phenoxide ligand, with the resonances of the phenoxide slightly shifted (compared to 2) toward those of phenol and, vice versa, the resonances of the associated phenol shifted toward those of a phenoxide anion. As also deduced from the ${ }^{1} \mathrm{H}$ NMR spectrum, rapid phenol/phenoxide exchange is indicated by the ${ }^{13} \mathrm{C}$ NMR spectrum of 7 , and at $23^{\circ} \mathrm{C}$ only one set of resonances is observed for the phenolate moieties, with chemical shifts between those of phenol and 5. The ipso carbon atoms of both phenolate moieties coalesce just below room temperature $\left(14^{\circ} \mathrm{C}\right)$ and are visible as a very broad signal at $162 \mathrm{ppm}$. The free energy of activation for the exchange process calculated from this coalescence in the ${ }^{13} \mathrm{C}$ NMR spectrum $\left(\Delta G^{*} \approx 12.9 \mathrm{kcal} / \mathrm{mol}\right)$ is comparable to that calculated from the ${ }^{1} \mathrm{H}$ NMR spectrum $\left(\Delta G^{*} \approx 12.7\right.$ $\mathrm{kcal} / \mathrm{mol}$ ). Distinct resonances of the phenoxide ligand and associated phenol are observed at $-50^{\circ} \mathrm{C}$ (Table V). For the platinum complex 8 cooling below room temper-

(25) (a) Krafft, T. E.; Hejna, C. I.; Smith, J. S. Inorg. Chem. 1990, 29 , 2682. (b) Noyori, R.; Nishida, I.; Sakata, J. Tetrahedron Lett. 1981, 22, 3993 .

(26) Johnson, L. F.; Jankowski, W. C. Carbon-13 NMR Spectra; Wiley: New York, 1972 
ature is not required in order to see two sets of resonances originating from the phenoxide ligand and associated phenol; this further corroborates slower exchange in the platinum complex 8 than in the palladium analogue 7 . Likewise, the ${ }^{13} \mathrm{C}$ NMR spectrum of the platinum catecholate 10 shows six distinct signals stemming from the catecholate unit at room temperature, but the palladium catecholate 9 requires cooling below room temperature in order to block phenol/phenoxide exchange on the ${ }^{13} \mathrm{C}$ NMR time scale; six distinct signals of the catecholate ligand are observed at $-30^{\circ} \mathrm{C} .{ }^{27}$ The carbon atoms of the phenoxide ligands in the platinum complexes did not show coupling with the platinum center, but some of the carbon atoms of the NCN ligand did show coupling, as has been observed earlier for other $\mathrm{Pt}^{\mathrm{II}}(\mathrm{NCN})$ derivatives. ${ }^{21}$ The satellites from ${ }^{1} J\left({ }^{195} \mathrm{Pt},{ }^{13} \mathrm{C}\right)$ for the ipso carbon atom of the NCN ligand were not observed.

Association Constants for Hydrogen Bonding of Phenol to 2 and 3. Equilibrium constants at various temperatures for the association of phenol with 2 and 3 were determined with the Scatchard method, which is based on the change of the chemical shift of the $\mathrm{OH}$ resonance (at fixed total concentration of phenol) with variation of the concentration of the hydrogen-bond acceptor (i.e. the palladium phenoxide) ${ }^{28}$ Thermodynamic parameters are determined from the equilibrium constant and its temperature dependence. The Scatchard method has been used successfully for the determination of association constants for late transition metal mono(phenoxides). ${ }^{18, c-e}$ Its use in the case of bis(phenoxides) is more complicated because there are two binding sites for phenol in one molecule. The consequences of the existence of multiple equilibria for the determination of equilibrium constants with spectroscopic techniques have been extensively discussed by Deranleau. ${ }^{2} 19$ The Scatchard plot only gives a straight line when all microscopic constants, both equilibrium constants $k$ and chemical shifts, are identical. In that case, the association constant obtained from the slope of the Scatchard plot is a microscopic equilibrium constant $k$, which describes the association of phenol to a $\mathrm{Pd}-\mathrm{OPh}$ unit. In the case of identical microscopic parameters, each of these $\mathrm{Pd}-\mathrm{OPh}$ units within the same molecule acts as if it is independent of the other $\mathrm{Pd}-\mathrm{OPh}$ binding site, and association of phenol to one phenoxide group has no influence on the capability of the other phenoxide unit to bind a phenol molecule. For the palladium phenoxides 2 and 3, some of the microscopic constants are necessarily identical because of the symmetry of the molecules (see supplementary material), and phenol association to one of the phenoxide ligands can be expected to have little effect on phenol association to the other phenoxo group because of their mutual trans positions. Good linear Scatchard plots were obtained at all temperatures in $\mathrm{CDCl}_{3}$ solution, both for 2 and 3 . However, one must be cautious in drawing the conclusion that this indicates that the microscopic constants are indeed all identical, since curvature is only detected when the measurements are done over a wide range of the saturation factor. It is not easy to achieve such a wide range of saturation in practice because of experimental limitations, in particular the relatively low boiling point of $\mathrm{CDCl}_{3}$,

(27) The chemical shifts of the carbon atoms in the catecholate ligand in 9 (at $-30^{\circ} \mathrm{C}$ ) and 10 attached to the anionic oxygen atom and to the OH group agree well with those calculated by using increment values of $\mathrm{O}^{-}$and $\mathrm{OH}$ substituents on a benzene ring; see: Stothers, J. B. Carbon-13 NMR Spectroscopy; Academic: New York, 1972; p 197.

(28) Reference $2 b, p 173$.

(29) Deranleau, D. A. J. Am. Chem. Soc. 1969, 91, 4050. See also: Deranleau, D. A. J. Am. Chem. Soc. 1969, 91, 4044.

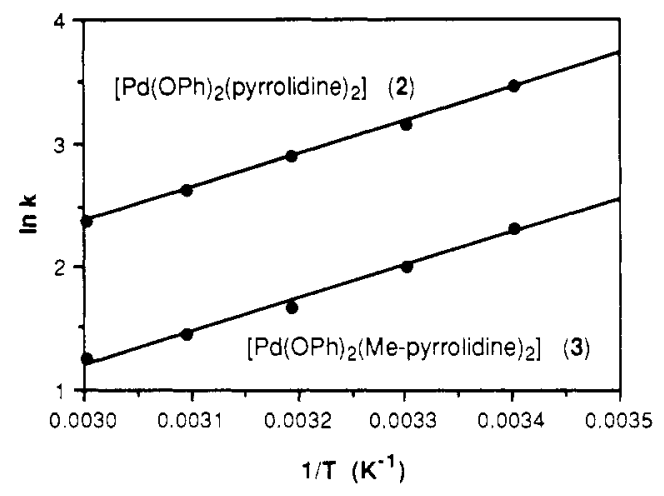

Figure 6. Van 't Hoff plots $(\ln k$ vs $1 / T)$ for the association of phenol with bis(pyrrolidine)palladium diphenoxide (2) and with bis $(N$-methylpyrrolidine)palladium diphenoxide (3).

which limits the range of temperatures that can be used, ${ }^{30}$ and the necessity to use a high ratio of $\mathrm{Pd}-$ phenoxide/ phenol concentration, which is a condition made in the derivation of the Scatchard equation. Therefore, the Scatchard plots indicate at most that the microscopic equilibrium constants are of similar order of magnitude. This is partly justified by the actual isolation of the bis(phenol) adduct 4 as a very stable compound, which shows that attachment of one phenol molecule does not greatly diminish the affinity of the other phenoxide ligand for phenol association.

Van 't Hoff plots for the association of phenol to 2 and 3 are shown in Figure 6. The measurements for 3 have been done in duplicate, with different solutions, and were found to be highly reproducible. As can be seen, complex 2 has a greater affinity than 3 for phenol association. The nearly identical slopes of both lines, but with different intercepts, indicate that the unequal affinities for phenol association are solely due to differences in $\Delta S^{\circ}$ and are not due to different $\Delta H^{\circ}$ values. Thermodynamic parameters obtained from the van ' $t$ Hoff plot for phenol association to a phenoxide ligand in 2 are (at $298 \mathrm{~K}$ ) $k=28.1 \mathrm{~L} / \mathrm{mol}$, $\Delta G^{\circ}=-2.0 \mathrm{kcal} / \mathrm{mol}, \Delta H^{\circ}=-5.4 \mathrm{kcal} / \mathrm{mol}$, and $\Delta S^{\circ}=$ $-11.4 \mathrm{eu}$, whereas the values for 3 are (at $298 \mathrm{~K}$ ) $k=8.6$ $\mathrm{L} / \mathrm{mol}, \Delta G^{\circ}=-1.3 \mathrm{kcal} / \mathrm{mol}, \Delta H^{\circ}=-5.3 \mathrm{kcal} / \mathrm{mol}$, and $\Delta S^{\circ}=-13.6 \mathrm{eu}$. The fact that both complexes have nearly identical $\Delta H^{\circ}$ values suggests that $\mathrm{N}-\mathrm{H} \ldots \mathrm{O}$ hydrogen bonding is unimportant in solution for 2. The enthalpy values are typical for medium to strong hydrogen bonding, which is in line with the conclusion drawn on the basis of the $\mathrm{O}-\mathrm{H}$ stretching frequency in the infrared spectrum of 4. The enthalpy values are very similar to those of methylpalladium (or methylplatinum) phenoxides and alkoxides with trimethylphosphine donors (in $\mathrm{CD}_{2} \mathrm{Cl}_{2}$ or toluene- $\left.d_{8}\right) .{ }^{1 \mathrm{c}-\mathrm{T}}$ The $\mathrm{O} \ldots \mathrm{O}$ bond distance observed in the crystal structure of 4 (2.638 (4) $\AA$ ), another indicator of the strength of the hydrogen bond, is also very similar to the length found in these organometallic phenoxides $(2.59-2.63 \AA)$. This adds further strength to the reliability of the obtained values. The enthalpy values are substantially smaller than the values obtained for rhodium(I) phenoxides in cyclohexane $\left(\Delta H^{\circ}=-14.0 \mathrm{kcal} / \mathrm{mol}\right)$ or benzene $\left(\Delta H^{\circ}=-9.7\right.$ and $\left.-11.4 \mathrm{kcal} / \mathrm{mol}\right),{ }^{1 \text { a }}$ which is likely to be due at least in part to the more apolar nature of these solvents that the relatively acidic chloroform (used in our measurements). ${ }^{31}$

(30) Lowering the temperature below room temperature in order to achieve a wider range of saturation is of little use, since at room temperature saturation is already nearly complete at the high $\mathrm{Pd}-\mathrm{phen}$ oxide/phenol ratio that must be used. 
It is surprising that the enthalpy values for association of phenol with the trans-palladium diphenoxides 2 and 3 are so close to those of palladium phenoxides with trimethylphosphine ligands, which have a strongly $\sigma$-donating methyl group in trans position with respect to the phenoxide group. It has been suggested that hydrogen-bond acceptor ability increases with the electron-donating capacity of the trans ligand, ${ }^{1 d}$ but the present data do not support this view since a phenoxide ligand has a much lower trans influence than a methyl group. A possible explanation is that the effect of replacing a methyl group by a phenoxo group is counterbalanced by simultaneous substitution of amine ligands for trimethylphosphine. Since the nucleophilicity of a metal center is greater with purely $\sigma$-donating amine ligands compared to that with phosphines, such an effect could in principle offset the simultaneous decrease in nucleophilicity upon replacing a methyl group by a phenoxide ligand. However, this view is not supported by the ${ }^{13} \mathrm{C}$ spectra of the diphenoxides 1-3, which clearly show less resonance stabilization than is indicated by literature data for trans-bis(trimethylphosphine)methylpalladium phenoxide. ${ }^{\text {Id }}$ For this reason, we favor the following explanation. Although increase of the $\sigma$-donor strength of the ligand in trans position may lead to a higher negative charge on the phenoxide group as a whole, it does not necessarily increase the negative charge on the oxygen atom since the negative charge within the phenoxo group becomes spread out over the aromatic ring via resonance stabilization. Stronger charge delocalization in the organometallic (NCN) phenoxide complexes compared to the diphenoxides was already concluded above from X-ray, IR, and ${ }^{13} \mathrm{C}$ NMR data. It is known that charge delocalized anions, including phenoxide, form weaker hydrogen bonds than nondelocalized anions. ${ }^{32}$ Thus, the charge on oxygen remains essentially equal upon substitution of methyl for phenoxide in a trans position and, consequently, the hydrogen-bond strength (in terms of enthalpy and $0 \ldots 0$ bond length) does not change. However, the fact that hydrogen bonding in 7 is clearly stronger than in 4 (according to IR and X-ray diffraction) indicates that this explanation is not fully sufficient and that other factors also influence the strength of the hydrogen bond. ${ }^{33}$

\section{Conclusions}

Despite the common belief that palladium and platinum, as "soft" metals, have a low affinity for anionic oxygen donors, palladium and platinum phenoxides (without intramolecular coordination) containing amine ligands prove to be quite stable, especially when the coordination sphere is complemented by chelating ligands. Spectroscopic data indicate that the phenoxide ligand is electron rich, in particular when strong $\sigma$-donors are present in a trans position with respect to the phenoxo group. These phenoxides have a strong tendency to be associated with phenol through hydrogen bonding, both in solution as well as in the solid state. An example of $\mathrm{N}-\mathrm{H}$... O hydrogen bonding

(31) It is well-known that chloroform can form $\mathrm{C}-\mathrm{H}$...O hydrogen bonds; see: (a) Green, R. D. Hydrogen Bonding by C-H Groups; MacMillan: London, 1974. (b) Desiraju, G. R. Acc. Chem. Res. 1991, 24, 290 (32) Meot-Ner (Mautner), M.; Sieck, L. W. J. Am. Chem. Soc. 1986 108,7525 .

(33) Scatchard measurements for association of phenol to 5 have been attempted but were hampered by the fact that the palladium phenoxide catalyzes the $\mathrm{H} / \mathrm{D}$ exchange between phenol and $\mathrm{CDCl}_{3}$. This is a serious problem at the low concentration of phenol that is necessary to fulfill the condition of a high $\mathrm{Pd}-$ phenoxide/phenol ratio. $\mathrm{H} / \mathrm{D}$ exchange was also observed for 2 and phenol at $60^{\circ} \mathrm{C}$ in $\mathrm{CDCl}_{3}$ but occurs much more slowly. in the solid state has also been found. The phenoxide ligand is labile and exchanges readily with (associated) phenol. This process occurs more readily in arylpalladium phenoxides than in palladium diphenoxides. As expected, ${ }^{34}$ platinum phenoxides are kinetically more inert in these substitution reactions than the corresponding palladium phenoxides. Thermodynamic parameters for the association of phenol with two palladium diphenoxides have been determined. These data show that a strong trans-positioned $\sigma$-donor is not a prerequisite for strong hydrogen bonding (in terms of $\Delta H^{\circ}$ ) and that the strength of the hydrogen bond is determined by other factors as well. Investigation of their reactivity toward insertion in the $\mathrm{Pd}-\mathrm{O}$ or $\mathrm{Pt}-\mathrm{O}$ bond and $\mathrm{C}-\mathrm{H}$ activation merits further investigation.

\section{Experimental Section}

General Methods. Reactions were performed in an atmosphere of nitrogen using standard Schlenk techniques, unless stated otherwise. $\mathrm{C}_{6} \mathrm{H}_{6}, \mathrm{Et}_{2} \mathrm{O}, \mathrm{THF}$, and pentane were freshly distilled from sodium benzophenone ketyl. $\mathrm{CH}_{2} \mathrm{Cl}_{2}$ was distilled from calcium hydride. ${ }^{1} \mathrm{H}$ - and ${ }^{13} \mathrm{C}-\mathrm{NMR}$ spectra were recorded on a Bruker $\mathrm{AC} 200$ spectrometer at $297 \mathrm{~K}$. Infrared spectra $(\mathrm{KBr}$ disks) and UV/vis spectra $\left(\mathrm{CH}_{2} \mathrm{Cl}_{2}\right.$ solution) were recorded on Perkin-Elmer 283 and Cary 5 spectrophotometers, respectively. Elemental analyses were carried out by the Institute of Applied Chemistry (TNO), Zeist, The Netherlands, or by Dornis und Kolbe, Mikroanalytisches Laboratorium, Mülheim a. d. Ruhr, Germany. The starting materials $\mathrm{Pd}(\mathrm{dba})_{2}{ }^{35}$ (dba $=$ dibenzylideneacetone) and $\left[\mathrm{M}\left(\mathrm{C}_{6} \mathrm{H}_{3}\left(\mathrm{CH}_{2} \mathrm{NMe}_{22}\right)_{2}-6\right)\left(\mathrm{H}_{2} \mathrm{O}\right)\right] \mathrm{BF}_{4}(\mathrm{M}$ $=\mathrm{Pd}, \mathrm{Pt})^{36}$ were prepared according to literature procedures.

Synthesis of $\left[\mathbf{P d}(\mathrm{OPh})_{2}\right.$ (tmeda)] (1). To a solution of $\mathrm{Pd}$ $(\mathrm{OAc})_{2}(1.27 \mathrm{~g} ; 5.66 \mathrm{mmol})$ and tmeda $(0.69 \mathrm{~g} ; 5.94 \mathrm{mmol})$ in $\mathrm{CH}_{2} \mathrm{Cl}_{2}(80 \mathrm{~mL})$ was added a solution of $\mathrm{NaOPh}(1.32 \mathrm{~g} ; 11.34$ $\mathrm{mmol}$ ) in THF (15 mL). The resulting dark-red mixture was stirred for $1 \mathrm{~h}$, after which the solution was evaporated to dryness under reduced pressure. The residue was extracted with $\mathrm{CH}_{2} \mathrm{Cl}_{2}$ $(3 \times 30 \mathrm{~mL})$, and the extracts were filtered off over Celite. The filtrate was evaporated to a small volume (ca. $20 \mathrm{~mL}$ ). The pure product was obtained by diffusion of $\mathrm{Et}_{2} \mathrm{O}$ into this solution. The resulting long, needle-shaped orange-red crystals were washed with $\mathrm{Et}_{2} \mathrm{O}(3 \times 20 \mathrm{~mL})$ and pentane $(1 \times 20 \mathrm{~mL})$ and dried in vacuo. Yield: $1.93 \mathrm{~g}(84 \%)$. Mp: $172^{\circ} \mathrm{C}$ dec. Anal. Calcd: $\mathrm{C}$. 52,$87 ; \mathrm{H}, 6.42 ; \mathrm{N}, 6.85$. Found: C, 52.69; H, 6.47; N, 6.94.

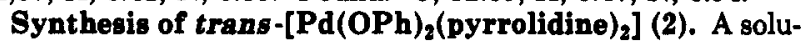
tion of pyrrolidine $(0.72 \mathrm{~g} ; 10.1 \mathrm{mmol})$ in $\mathrm{CH}_{2} \mathrm{Cl}_{2}(5 \mathrm{~mL})$ was added to a solution of $\mathrm{Pd}(\mathrm{OAc})_{2}(1.12 \mathrm{~g} ; 5.0 \mathrm{mmol})$ in $\mathrm{CH}_{2} \mathrm{Cl}_{2}(200 \mathrm{~mL})$ under air. To this solution was added, slowly and with vigorous stirring, a solution of $\mathrm{NaOPh}(1.16 \mathrm{~g} ; 10.0 \mathrm{mmol})$ in a minimum of methanol (ca. $5 \mathrm{~mL}$ ). This mixture was stirred for $1 \mathrm{~h}$. The resulting solution was filtered off over Celite. The solution was evaporated to dryness under reduced pressure, and the residue was redissolved in $\mathrm{CH}_{2} \mathrm{Cl}_{2}(10 \mathrm{~mL})$. After filtration, the solution was again evaporated to dryness. The crude product was recrystallized by diffusion of $\mathrm{Et}_{2} \mathrm{O}$ into a $\mathrm{CH}_{2} \mathrm{Cl}_{2}$ solution of the product. The resulting orange crystals (suitable for $\mathrm{X}$-ray diffraction) were washed with $\mathrm{Et} \mathrm{t}_{2} \mathrm{O}$ and dried under vacuum to afford the pure product in $89 \%$ yield $(1.93 \mathrm{~g} ; 4.4 \mathrm{mmol})$. The compound decomposes slowly at room temperature and should be stored at low temperature $\left(-30^{\circ} \mathrm{C}\right)$. Mp: $145^{\circ} \mathrm{C}\left(\operatorname{dec}>115^{\circ} \mathrm{C}\right)$. Anal. Calcd: C, 55.24; H, 6.49; N, 6.44. Found: C, 55.10; H, 6.72; N, 6.39.

Synthesis of trans-[Pd(OPh $\left.)_{2}(N \text {-methylpyrrolidine })_{2}\right]$ (3). This compound is prepared in $90 \%$ yield as an orange-red material as described for 2 , but using $N$-methylpyrrolidine as ligand. The compound crystallizes very easily; even rotary evaporation affords single crystals. The compound should be stored at low tem-

(34) Cotton, F. A.; Wilkinson, G. Advanced Inorganic Chemistry, 5th ed.; Wiley: New York, 1988; p 1288, 1297.

(35) Rettig, M. F.; Maitlis, P. M.; Cotton, F. A.; Webbs, T. R. Inorg. Synth. 1971, 134

(36) Grove, D. M.; van Koten, G.; Louwen, J. N.; Noltes, J. G.; Spek, A. L.; Ubbels, H. J. C. J. Am. Chem. Soc. 1982, 104, 6609 . 
Table VI. Crystal Data and Details of the Structure Determinations

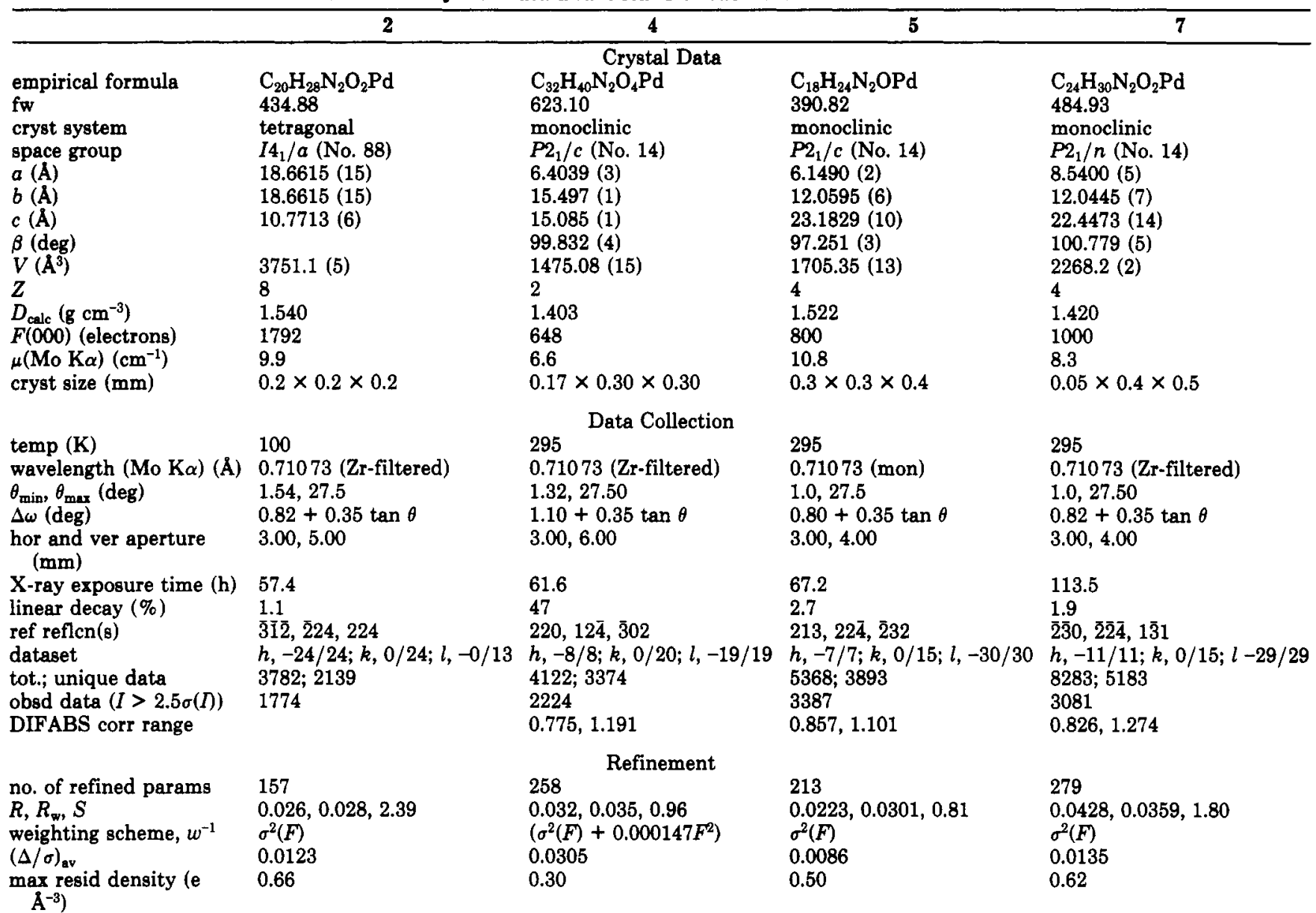

perature $\left(-30^{\circ} \mathrm{C}\right)$. Mp: $138^{\circ} \mathrm{C}\left(\operatorname{dec}>95^{\circ} \mathrm{C}\right)$. Anal. Calcd: $\mathrm{C}$, 57.07; H, 6.98; N, 6.05. Found: C, 56.91; H, 7.16; N, 6.03.

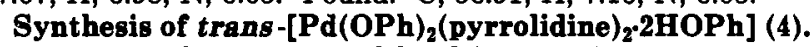
This compound was prepared by diffusion of pentane into a solution of $2(0.137 \mathrm{~g} ; 0.315 \mathrm{mmol})$ and phenol $(0.0637 \mathrm{~g} ; 0.677$ $\mathrm{mmol})$ in $\mathrm{CH}_{2} \mathrm{Cl}_{2}(3 \mathrm{~mL})$. The resulting yellow-orange crystals (suitable for X-ray diffraction) were washed with pentane ( $2 \times$ $20 \mathrm{~mL}$ ) and air-dried. Yield: $0.16 \mathrm{~g}(82 \%)$. Mp: $122^{\circ} \mathrm{C}$. Anal. Calcd: C, 61.68; H, 6.47; N, 4.50. Found: C, 61.61; H, 6.70; N, 4.54.

Synthesis of $\left[\mathrm{PdBr}\left(\mathrm{C}_{6} \mathrm{H}_{3}\left(\mathrm{CH}_{2} \mathrm{NMe}_{2}\right\}_{2}-2,6\right)\right]$. To a solution of $\mathrm{Pd}(\mathrm{dba})_{2}(3.63 \mathrm{~g} ; 6.3 \mathrm{mmol})$ in $\mathrm{C}_{6} \mathrm{H}_{6}(125 \mathrm{~mL})$ was added a solution of $\mathrm{BrC}_{6} \mathrm{H}_{3}\left(\mathrm{CH}_{2} \mathrm{NMe}_{2}\right)_{2}-2,6(2.00 \mathrm{~g} ; 7.3 \mathrm{mmol})$ in $\mathrm{C}_{6} \mathrm{H}_{6}(15$ $\mathrm{mL}$ ) under a nitrogen atmosphere. The deep purple mixture turned yellow-green upon slowly heating to $75^{\circ} \mathrm{C}$ in $25 \mathrm{~min}$. After a further 5 min of stirring at this temperature, the mixture was allowed to cool down to room temperature. Traces of metallic palladium were filtered off over Celite, and the filter material and residue were washed with $\mathrm{CH}_{2} \mathrm{Cl}_{2}(2 \times 50 \mathrm{~mL})$. The combined filtrates were evaporated to dryness with a rotary evaporator. The remaining oil was triturated with $\mathrm{Et}_{2} \mathrm{O}(50 \mathrm{~mL})$. The resulting yellow solid was washed with $\mathrm{Et}_{2} \mathrm{O}(50 \mathrm{~mL})$ and pentane $(5 \times 50$ $\mathrm{mL}$ ). The remaining light-yellow powder was dried in vacuo. To remove the last traces of dba, the product was recrystallied by diffusion of a mixture of $\mathrm{Et}_{2} \mathrm{O}$ and pentane (1:1) into a $\mathrm{CH}_{2} \mathrm{Cl}_{2}$ solution of the product. The recrystallized product was washed with pentane $(3 \times 30 \mathrm{~mL})$ and dried in vacuo. Yield: $2.09 \mathrm{~g}(88 \%)$. The product was identical to that obtained via an alternative route using the lithiated derivative $\left.\left[\mathrm{LiC}_{6} \mathrm{H}_{3} \mathrm{CH}_{2} \mathrm{NMe}_{2}\right\}_{2}-2,6\right]_{2}{ }^{36}$

Synthesis of $\left[\mathrm{Pd}(\mathrm{OPh})\left(\mathrm{C}_{6} \mathrm{H}_{3}\left(\mathrm{CH}_{2} \mathrm{NMe}_{2}\right\}_{2}-2,6\right)\right](5)$. To a stirred solution of $\left[\mathrm{Pd}\left(\mathrm{C}_{6} \mathrm{H}_{3}\left(\mathrm{CH}_{2} \mathrm{NMe}_{2}\right\}_{2}-2,6\right)\left(\mathrm{H}_{2} \mathrm{O}\right)\right] \mathrm{BF}_{4}(0.81 \mathrm{~g}$; $2.0 \mathrm{mmol})$ in $\mathrm{CH}_{2} \mathrm{Cl}_{2} / \mathrm{THF}(1: 1 ; 60 \mathrm{~mL})$ was added a solution of $\mathrm{NaOPh}(0.25 \mathrm{~g} ; 2.15 \mathrm{mmol})$ in $\mathrm{CH}_{2} \mathrm{Cl}_{2} / \mathrm{THF}(1: 1 ; 10 \mathrm{~mL})$. After 30 min of stirring, the solvents were removed under reduced pressure. The residue was extracted with $\mathrm{CH}_{2} \mathrm{Cl}_{2}(2 \times 30 \mathrm{~mL})$, and the extracts were filtered off over Celite. The filtrate was evaporated in vacuo until solid product began to precipitate. To this emulsion was added just enough $\mathrm{CH}_{2} \mathrm{Cl}_{2}$ to dissolve the precipitate. The pure product was obtained by slow addition of pentane to this gently shaken solution. The resulting microcrystalline, yellow product was washed with pentane $(30 \mathrm{~mL})$ and dried in vacuo. Yield: $0.73 \mathrm{~g}(93 \%)$. Crystals suitable for X-ray diffraction were obtained by diffusion of $\mathrm{Et}_{2} \mathrm{O}$ into a $\mathrm{CH}_{2} \mathrm{Cl}_{2}$ solution of 5. Mp: $200^{\circ} \mathrm{C}\left(\mathrm{dec}>182^{\circ} \mathrm{C}\right)$. Anal. Calcd: C, 55.32; H, 6.19; N, 7.17. Found: C, 55.13; H, 6.37; N, 7.09.

Synthesis of $\left[\mathrm{Pt}(\mathrm{OPh})\left(\mathrm{C}_{6} \mathrm{H}_{3}\left(\mathrm{CH}_{2} \mathrm{NMe}_{2}\right\}_{2}-2,6\right)\right]$ (6). This compound was prepared from $\left.\left[\mathrm{Pt}\left(\mathrm{C}_{6} \mathrm{H}_{3} \mid \mathrm{CH}_{2} \mathrm{NMe}_{2}\right]_{2}-2,6\right)\left(\mathrm{H}_{2} \mathrm{O}\right)\right] \mathrm{BF} 4$ via a procedure similar to that described for 5 . Yield: $74 \%$. Dec: $>215^{\circ} \mathrm{C}$. Anal. Calcd: C, 45.09; H, 5.05; N, 5.84. Found: C, 44.98; H, 5.08; N, 5.89 .

Synthesis of [Pd(OPh) $\left.\left(\mathrm{C}_{6} \mathrm{H}_{3}\left(\mathrm{CH}_{2} \mathrm{NMe}_{2}\right)_{2}-2,6\right) \cdot \mathrm{HOPh}\right]$ (7). To a solution of $5(0.20 \mathrm{~g} ; 0.5 \mathrm{mmol})$ in $\mathrm{CH}_{2} \mathrm{Cl}_{2}(15 \mathrm{~mL})$ was added a solution of phenol $(0.07 \mathrm{~g} ; 0.74 \mathrm{mmol})$ in $\mathrm{CH}_{2} \mathrm{Cl}_{2}(5 \mathrm{~mL})$. This mirture was stirred for $20 \mathrm{~min}$, after which the solvent was evaporated under reduced pressure, until some solid began to precipitate. To this emulsion was added just enough $\mathrm{CH}_{2} \mathrm{Cl}_{2}$ to dissolve the precipitate. The product was obtained by slowly adding pentane to this gently shaken solution. The precipitate was washed with pentane $(2 \times 20 \mathrm{~mL})$ and dried in vacuo. Yield: $0.25 \mathrm{~g}(100 \%)$ of 7 as a microcrystalline yellow substance. Mp: $160^{\circ} \mathrm{C}$. Anal. Calcd: C, 59.44; H, 6.24; N, 5.78. Found: C, 59.10; $\mathrm{H}, 6.08 ; \mathrm{N}, 5.88$.

Synthesis of $\left.\left[\mathrm{Pt}(\mathrm{OPh})\left(\mathrm{C}_{6} \mathrm{H}_{3} \mathrm{CH}_{2} \mathrm{NMe}_{2}\right\}_{2}-2,6\right) \cdot \mathrm{HOPh}\right](8)$. This complex was obtained in quantitative yield as a white microcrystalline solid by addition of phenol to 6 as described above for the Pd analogue 7. $\mathrm{Mp}: 170^{\circ} \mathrm{C}$. Anal. Calcd: C, $50.25 ; \mathrm{H}$, $5.27 ; \mathrm{N}, 4.88$. Found: C, 50.31; H, 5.25; N, 4.93.

Synthesis of $\left[\mathrm{Pd}\left(\mathrm{OC}_{6} \mathrm{H}_{4} \mathrm{OH}-2\right)\left(\mathrm{C}_{6} \mathrm{H}_{3}\left\{\mathrm{CH}_{2} \mathrm{NMe}_{2}\right\}_{2}-2,6\right)\right]$ (9). To a solution of $\left[\mathrm{Pd}\left(\mathrm{C}_{6} \mathrm{H}_{3}\left\langle\mathrm{CH}_{2} \mathrm{NMe}_{2}\right\}_{2}-2,6\right)\left(\mathrm{H}_{2} \mathrm{O}\right)\right] \mathrm{BF}_{4}(0.55 \mathrm{~g} ; 1.37$ $\mathrm{mmol})$ in $\mathrm{CH}_{2} \mathrm{Cl}_{2} / \mathrm{THF}(4: 1 ; 50 \mathrm{~mL})$ was added a solution of a $\mathrm{NaOPh}(0.17 \mathrm{~g} ; 1.46 \mathrm{mmol})$ in $\mathrm{CH}_{2} \mathrm{Cl}_{2} / \mathrm{THF}(1: 1 ; 10 \mathrm{~mL})$. This mixture was stirred for 30 min, after which the solvents were removed in vacuo. The solid residue was extracted with $\mathrm{CH}_{2} \mathrm{Cl}_{2}$ (30 mL), and the $\mathrm{CH}_{2} \mathrm{Cl}_{2}$ solution was filtered over Celite. To 
Table VII. Final Coordinates and Equivalent Isotropic Thermal Parameters with Esd's in Parentheses of the Non-Hydrogen Atoms of 2

\begin{tabular}{lllll}
\hline atom & \multicolumn{1}{c}{$x$} & \multicolumn{1}{c}{$y$} & \multicolumn{1}{c}{$z$} & $U(\mathrm{eq})\left(\AA^{2}\right)$ \\
\hline $\mathrm{Pd}$ & 0 & $1 / 4$ & $0.48119(2)$ & $0.0143(1)$ \\
$\mathrm{O}(1)$ & $0.04752(10)$ & $0.15394(10)$ & $0.49160(17)$ & $0.0194(5)$ \\
$\mathrm{N}(1)$ & $0.09908(12)$ & $0.29961(12)$ & $0.4922(2)$ & $0.0195(6)$ \\
$\mathrm{C}(1)$ & $0.06991(13)$ & $0.12043(13)$ & $0.3892(2)$ & $0.0178(6)$ \\
$\mathrm{C}(2)$ & $0.10566(14)$ & $0.05482(14)$ & $0.4005(2)$ & $0.0203(7)$ \\
$\mathrm{C}(3)$ & $0.13251(15)$ & $0.01969(15)$ & $0.2973(3)$ & $0.0251(8)$ \\
$\mathrm{C}(4)$ & $0.12378(16)$ & $0.04772(16)$ & $0.1793(3)$ & $0.0290(8)$ \\
$\mathrm{C}(5)$ & $0.08751(18)$ & $0.11153(17)$ & $0.1660(3)$ & $0.0315(9)$ \\
$\mathrm{C}(6)$ & $0.06013(16)$ & $0.14779(15)$ & $0.2688(3)$ & $0.0252(8)$ \\
$\mathrm{C}(7)$ & $0.10512(15)$ & $0.37519(14)$ & $0.4501(3)$ & $0.0246(8)$ \\
$\mathrm{C}(8)$ & $0.18578(16)$ & $0.39062(16)$ & $0.4411(3)$ & $0.0282(8)$ \\
$\mathrm{C}(9)$ & $0.22266(16)$ & $0.31849(18)$ & $0.4494(4)$ & $0.0370(10)$ \\
$\mathrm{C}(10)$ & $0.16250(15)$ & $0.26404(16)$ & $0.4359(3)$ & $0.0313(9)$
\end{tabular}

Table VIII. Final Coordinates and Equivalent Isotropic Thermal Parameters with Esd's in Parentheses of the Non-Hydrogen Atoms of 4

\begin{tabular}{lllll}
\hline \multicolumn{1}{c}{ atom } & \multicolumn{1}{c}{$x$} & \multicolumn{1}{c}{$y$} & \multicolumn{1}{c}{$z$} & $U(\mathrm{eq})\left(\AA^{2}\right)$ \\
\hline $\mathrm{Pd}$ & 0 & 0 & 0 & $0.0296(1)$ \\
$\mathrm{O}(1)$ & $0.1239(3)$ & $0.09183(14)$ & $0.08846(14)$ & $0.0368(7)$ \\
$\mathrm{N}(1)$ & $-0.2143(4)$ & $0.09114(18)$ & $-0.05582(19)$ & $0.0352(9)$ \\
$\mathrm{C}(1)$ & $0.0809(5)$ & $0.0908(2)$ & $0.1731(2)$ & $0.0334(10)$ \\
$\mathrm{C}(2)$ & $0.2111(7)$ & $0.1349(3)$ & $0.2411(3)$ & $0.0488(12)$ \\
$\mathrm{C}(3)$ & $0.1665(8)$ & $0.1375(3)$ & $0.3268(3)$ & $0.0583(16)$ \\
$\mathrm{C}(4)$ & $-0.0094(8)$ & $0.0963(3)$ & $0.3478(3)$ & $0.0575(16)$ \\
$\mathrm{C}(5)$ & $-0.1375(7)$ & $0.0525(3)$ & $0.2820(3)$ & $0.0563(16)$ \\
$\mathrm{C}(6)$ & $-0.0930(6)$ & $0.0489(3)$ & $0.1959(3)$ & $0.0463(14)$ \\
$\mathrm{C}(7)$ & $-0.1327(7)$ & $0.1611(3)$ & $-0.1075(3)$ & $0.0535(16)$ \\
$\mathrm{C}(8)$ & $-0.3296(7)$ & $0.2117(3)$ & $-0.1499(3)$ & $0.0639(17)$ \\
$\mathrm{C}(9)$ & $-0.5088(7)$ & $0.1473(3)$ & $-0.1588(4)$ & $0.0622(17)$ \\
$\mathrm{C}(10)$ & $-0.4150(7)$ & $0.0648(3)$ & $-0.1144(3)$ & $0.0547(14)$ \\
$\mathrm{O}(2)$ & $0.4962(5)$ & $0.15638(18)$ & $0.0716(2)$ & $0.0573(10)$ \\
$\mathrm{C}(11)$ & $0.5154(6)$ & $0.2442(2)$ & $0.0812(2)$ & $0.0418(11)$ \\
$\mathrm{C}(12)$ & $0.7176(7)$ & $0.2775(3)$ & $0.1021(3)$ & $0.0640(17)$ \\
$\mathrm{C}(13)$ & $0.7474(9)$ & $0.3652(3)$ & $0.1089(4)$ & $0.0765(19)$ \\
$\mathrm{C}(14)$ & $0.5776(10)$ & $0.4204(3)$ & $0.0959(4)$ & $0.0760(19)$ \\
$\mathrm{C}(15)$ & $0.3765(9)$ & $0.3864(3)$ & $0.0755(3)$ & $0.0654(17)$ \\
$\mathrm{C}(16)$ & $0.3448(6)$ & $0.2983(3)$ & $0.0686(3)$ & $0.0474(12)$
\end{tabular}

this solution of in situ generated 5 was added a solution of catechol $(0.16 \mathrm{~g} ; 1.45 \mathrm{mmol})$ in $\mathrm{CH}_{2} \mathrm{Cl}_{2} /$ THF $(1: 1 ; 10 \mathrm{~mL})$. The mixture was stirred for $30 \mathrm{~min}$ and evaporated to dryness. The solid residue was dissolved in a minimum amount of $\mathrm{CH}_{2} \mathrm{Cl}_{2}$, and the product was precipitated as a white powder by subsequent dropwise addition of $\mathrm{Et}_{2} \mathrm{O}(10 \mathrm{~mL})$ and pentane $(10 \mathrm{~mL})$. After filtration, the product was washed with pentane $(3 \times 10 \mathrm{~mL})$ and dried in vacuo. Yield: $0.55 \mathrm{~g}(99 \%)$ as a white powder. $\mathrm{Mp:} 210$ ${ }^{\circ} \mathrm{C}$ dec. Calcd: C, $53.14 ; \mathrm{H}, 5.95 ; \mathrm{N}, 6.89$. Found: C, 53.25; H, $6.04 ; \mathrm{N}, 6.95$. The complex is air-sensitive in solution.

Synthesis of $\left[\mathrm{Pt}\left(\mathrm{OC}_{6} \mathrm{H}_{4} \mathrm{OH}-2\right)\left(\mathrm{C}_{6} \mathrm{H}_{3} \mathrm{CH}_{2} \mathrm{NMe}_{2} \mathrm{~S}_{2}-2,6\right)\right](10)$. To a solution of $6(0.12 \mathrm{~g} ; 0.25 \mathrm{mmol})$ in $\mathrm{CH}_{2} \mathrm{Cl}_{2}(15 \mathrm{~mL})$ was added a solution of catechol $(0.03 \mathrm{~g} ; 0.27 \mathrm{mmol})$ in $\mathrm{CH}_{2} \mathrm{Cl}_{2} / \mathrm{Et}_{2} \mathrm{O}$ (1:1; $5 \mathrm{~mL}$ ). This mixture was stirred for $30 \mathrm{~min}$, after which the solvents were removed in vacuo. The residue was washed with $\mathrm{Et}_{2} \mathrm{O}(1 \times 5 \mathrm{~mL})$ and pentane $(1 \times 15 \mathrm{~mL})(90 \%$ yield of crude product; pure according to ${ }^{1} \mathrm{H} \mathrm{NMR}$ ). The product was recrygtallized by diffusion of a mixture of $\mathrm{Et}_{2} \mathrm{O}$ /pentane (1:1) into a $\mathrm{CH}_{2} \mathrm{Cl}_{2}$ solution, yielding yellow crystals. Yield: $0.08 \mathrm{~g}(65 \%)$. Dec: $>215^{\circ} \mathrm{C}$. Anal. Calcd: $\mathrm{C}, 43.63 ; \mathrm{H}, 4.88 ; \mathrm{N}, 5.65$. Found: C, $43.60 ; \mathrm{H}, 4.81 ; \mathrm{N}, 5.61$.

Determination of Association Constants. Phenol $(0.0120$ g; $0.127 \mathrm{mmol})$ was dissolved in $\mathrm{CDCl}_{3}(15 \mathrm{~mL}$; dried on anhydrous $\mathrm{CaCl}_{2}$ ). Four NMR samples with accurately weighed amounts of palladium phenoxide ( 2 or 3 ) were prepared so as to give concentrations in the range $0.118-0.318 \mathrm{M}$ (ratio of concentration Pd phenoxide/phenol ranges from 14 to 37 ; i.e. the concentration ratio of phenoxide units/phenol ranges from 28 to 74). The chemical shift of the $\mathrm{OH}$ proton was measured at five different temperatures for each sample. The $\mathrm{OH}$ chemical shift of phenol in $\mathrm{CDCl}_{3}$ without added $\mathrm{Pd}$ phenoxide was also determined at each temperature. The microscopic association constant $k$ is calculated at each temperature on the basis of the Scatchard
Table IX. Final Coordinates and Equivalent Isotropic Thermal Parameters with Esd's in Parentheses of the Non-Hydrogen Atoms of 5

\begin{tabular}{lllll}
\hline atom & \multicolumn{1}{c}{$x$} & \multicolumn{1}{c}{$y$} & \multicolumn{1}{c}{$z$} & $U(\mathrm{eq})\left(\AA^{2}\right)$ \\
\hline $\mathrm{Pd}$ & $0.64477(2)$ & $0.59536(1)$ & $0.34879(1)$ & $0.0274(1)$ \\
$\mathrm{O}(1)$ & $0.8717(3)$ & $0.46450(14)$ & $0.34365(8)$ & $0.0437(5)$ \\
$\mathrm{N}(1)$ & $0.4549(3)$ & $0.56966(15)$ & $0.26813(8)$ & $0.0329(5)$ \\
$\mathrm{N}(2)$ & $0.7714(3)$ & $0.66101(17)$ & $0.43014(8)$ & $0.0343(6)$ \\
$\mathrm{C}(1)$ & $0.4509(3)$ & $0.71874(18)$ & $0.35034(9)$ & $0.0318(6)$ \\
$\mathrm{C}(2)$ & $0.2657(4)$ & $0.72375(19)$ & $0.30953(10)$ & $0.0366(7)$ \\
$\mathrm{C}(3)$ & $0.1240(4)$ & $0.8131(2)$ & $0.31033(12)$ & $0.0484(8)$ \\
$\mathrm{C}(4)$ & $0.1705(5)$ & $0.8942(2)$ & $0.35261(13)$ & $0.0523(10)$ \\
$\mathrm{C}(5)$ & $0.3543(5)$ & $0.88853(19)$ & $0.39378(13)$ & $0.0484(9)$ \\
$\mathrm{C}(6)$ & $0.4989(4)$ & $0.80011(18)$ & $0.39272(10)$ & $0.0370(7)$ \\
$\mathrm{C}(7)$ & $0.2353(4)$ & $0.6245(2)$ & $0.27007(11)$ & $0.0428(8)$ \\
$\mathrm{C}(8)$ & $0.5726(5)$ & $0.6252(2)$ & $0.22416(11)$ & $0.0455(8)$ \\
$\mathrm{C}(9)$ & $0.4217(5)$ & $0.4518(2)$ & $0.25222(12)$ & $0.0471(8)$ \\
$\mathrm{C}(10)$ & $0.7136(4)$ & $0.7822(2)$ & $0.43035(11)$ & $0.0424(7)$ \\
$\mathrm{C}(11)$ & $0.6611(5)$ & $0.6023(2)$ & $0.47465(11)$ & $0.0466(8)$ \\
$\mathrm{C}(12)$ & $1.0109(4)$ & $0.6451(3)$ & $0.44415(12)$ & $0.0494(9)$ \\
$\mathrm{C}(13)$ & $0.8623(4)$ & $0.3678(2)$ & $0.36849(10)$ & $0.0365(7)$ \\
$\mathrm{C}(14)$ & $0.6797(4)$ & $0.3310(2)$ & $0.39459(11)$ & $0.0416(8)$ \\
$\mathrm{C}(15)$ & $0.6774(5)$ & $0.2281(2)$ & $0.42030(12)$ & $0.0515(9)$ \\
$\mathrm{C}(16)$ & $0.8532(6)$ & $0.1564(2)$ & $0.42147(13)$ & $0.0592(10)$ \\
$\mathrm{C}(17)$ & $1.0328(5)$ & $0.1899(2)$ & $0.39573(13)$ & $0.0536(9)$ \\
$\mathrm{C}(18)$ & $1.0397(4)$ & $0.2928(2)$ & $0.37016(11)$ & $0.0445(8)$
\end{tabular}

Table X. Final Coordinates and Equivalent Isotropic Thermal Parameters with Esd's in Parentheses of the Non-Hydrogen Atoms of 7

\begin{tabular}{lllll}
\hline atom & \multicolumn{1}{c}{$x$} & $y$ & $z$ & $U(\mathrm{eq})\left(\AA^{2}\right)$ \\
\hline $\mathrm{Pd}$ & $0.66013(4)$ & $0.25723(4)$ & $0.02857(2)$ & $0.0314(1)$ \\
$\mathrm{O}(1)$ & $0.8317(4)$ & $0.3180(3)$ & $0.10325(18)$ & $0.0495(14)$ \\
$\mathrm{N}(1)$ & $0.4700(5)$ & $0.2212(3)$ & $0.07293(19)$ & $0.0354(16)$ \\
$\mathrm{N}(2)$ & $0.8005(5)$ & $0.2773(3)$ & $-0.0381(2)$ & $0.0415(16)$ \\
$\mathrm{C}(1)$ & $0.5211(5)$ & $0.1863(4)$ & $-0.0363(2)$ & $0.0337(16)$ \\
$\mathrm{C}(2)$ & $0.3896(5)$ & $0.1284(4)$ & $-0.0256(2)$ & $0.0343(16)$ \\
$\mathrm{C}(3)$ & $0.2904(6)$ & $0.0777(5)$ & $-0.0727(3)$ & $0.049(2)$ \\
$\mathrm{C}(4)$ & $0.3220(7)$ & $0.0857(5)$ & $-0.1317(3)$ & $0.050(2)$ \\
$\mathrm{C}(5)$ & $0.4541(7)$ & $0.1436(5)$ & $-0.1425(3)$ & $0.0462(17)$ \\
$\mathrm{C}(6)$ & $0.5547(6)$ & $0.1962(4)$ & $-0.0951(3)$ & $0.0395(17)$ \\
$\mathrm{C}(7)$ & $0.3794(6)$ & $0.1240(4)$ & $0.0412(3)$ & $0.0397(19)$ \\
$\mathrm{C}(8)$ & $0.3636(7)$ & $0.3202(4)$ & $0.0660(3)$ & $0.047(2)$ \\
$\mathrm{C}(9)$ & $0.5183(7)$ & $0.1958(5)$ & $0.1384(3)$ & $0.054(2)$ \\
$\mathrm{C}(10)$ & $0.6925(6)$ & $0.2707(5)$ & $-0.0990(2)$ & $0.0490(19)$ \\
$\mathrm{C}(11)$ & $0.9159(7)$ & $0.1841(5)$ & $-0.0329(3)$ & $0.058(3)$ \\
$\mathrm{C}(12)$ & $0.8892(8)$ & $0.3846(6)$ & $-0.0314(3)$ & $0.066(3)$ \\
$\mathrm{C}(13)$ & $0.8523(6)$ & $0.4217(4)$ & $0.1235(2)$ & $0.0375(17)$ \\
$\mathrm{C}(14)$ & $0.7521(6)$ & $0.5074(5)$ & $0.0975(2)$ & $0.0393(17)$ \\
$\mathrm{C}(15)$ & $0.7759(7)$ & $0.6157(5)$ & $0.1196(3)$ & $0.0465(19)$ \\
$\mathrm{C}(16)$ & $0.8998(7)$ & $0.6398(5)$ & $0.1670(3)$ & $0.055(2)$ \\
$\mathrm{C}(17)$ & $0.9977(8)$ & $0.5559(5)$ & $0.1917(3)$ & $0.064(2)$ \\
$\mathrm{C}(18)$ & $0.9759(7)$ & $0.4473(5)$ & $0.1705(3)$ & $0.055(2)$ \\
$\mathrm{O}(2)$ & $0.0545(5)$ & $0.1720(4)$ & $0.1221(2)$ & $0.0612(17)$ \\
$\mathrm{C}(19)$ & $0.0504(6)$ & $0.1053(5)$ & $0.1705(3)$ & $0.0392(17)$ \\
$\mathrm{C}(20)$ & $0.1382(7)$ & $0.0083(5)$ & $0.1746(3)$ & $0.052(2)$ \\
$\mathrm{C}(21)$ & $0.1381(8)$ & $-0.0629(6)$ & $0.2220(3)$ & $0.069(3)$ \\
$\mathrm{C}(22)$ & $0.0525(10)$ & $-0.0388(7)$ & $0.2651(3)$ & $0.082(3)$ \\
& & & &
\end{tabular}

equation (modified for the use of complexes containing two binding sites):

$\frac{\delta(\mathrm{OH})_{\mathrm{obs}}-\delta(\mathrm{OH})_{\mathrm{PhOH}}}{2[\mathrm{Pd} \text { phenoxide }]^{\circ}}=-k\left\{\delta(\mathrm{OH})_{\mathrm{obs}}-\delta(\mathrm{OH})_{\mathrm{PbOH}}\right\}+$ constant

Here $\delta(\mathrm{OH})_{\text {obe }}=$ chemical shift of the observed OH signal, $\delta$ $(\mathrm{OH})_{\mathrm{PhOH}}=$ chemical shift of free, uncomplexed phenol (ca. 4.5 ppm at the high dilution used), and $[\text { Pd phenoxide }]^{\circ}=$ concentration of 2 or 3 based on the weighed amount of palladium phenoxide.

X-ray Data Collection, Structure Determination, and Refinement of $2,4,5$, and 7 . Crystal data and numerical details of the structure determinations are given in Table VI. Crystals suitable for X-ray structure determination were mounted on a Lindemann glass capillary and transferred to an Enraf-Nonius CAD-4F $(2,4$, and 7$)$ sealed tube or CAD-4T on rotating anode $(10 \mathrm{~kW})$ diffractometer (5) for data collection. Lattice parameters were determined by least-squares fitting of the SET 4 setting angles 
of 25 reflections with $13.4^{\circ}<\theta<17.8^{\circ}, 13.4^{\circ}<\theta<17.8^{\circ}, 11.2^{\circ}$ $<\theta<14.4^{\circ}$, and $9.3^{\circ}<\theta<14.6^{\circ}$ for $2,4,5$, and 7 , respectively. The unit-cell parameters were checked for the presence of higher lattice symmetry. ${ }^{37}$ All data were collected with the $\omega / 2 \theta$ scan mode. Data were corrected for $\mathrm{Lp}$ and for the observed linear decay of the reference reflections. Absorption corrections were applied to 4, 5, and 7 using the DIFABS procedure. ${ }^{38}$ Standard deviations of the intensities as obtained by counting statistics were increased according to an analysis of the excess variance of the reference reflections: $\sigma^{2}(I)=\sigma_{a}^{2}(I)+(p I)^{2}$, with $p=0.019,0.207$, 0.014 , and 0.013 for $2,4,5$, and 7 , respectively. ${ }^{39}$ The structures were solved (SHELXS86) ${ }^{40}$ by automated Patterson methods followed by tangent expansion $(2,4)$ or automated direct methods $(5,7)$. Refinement on $F$ was carried out by full-matrix leastsquares techniques (SHELX76). ${ }^{41}$ The hydrogen atoms of 5 and 7 were included in the refinement on calculated positions $(\mathrm{C}-\mathrm{H}$ $=0.98 \AA$ ) riding on their carrier atoms. The hydrogen atoms of 2 and 4 , and the hydroxyl hydrogen of 7 , were located on difference Fourier maps; their coordinates were included in the refinment. All non-hydrogen atoms were refined with anisotropic thermal parameters; the hydrogen atoms of 2,5 , and 7 were refined with one common isotropic thermal parameter of 0.037 (3), 0.0593 (19), and 0.067 (4) respectively. $F_{\mathrm{c}}$ values of 5 and 7 were corrected for secondary extinction by refinement of an empirical isotropic

(37) Spek, A. L. J. Appl. Crystallogr. 1988, 21, 578.

(38) Walker, N.; Stuart, D. Acta Crystallogr. 1983, A39, 158.

(39) McCandlish, L. E.; Stout, G. H.; Andrews, L. C. Acta Crystallogr. 1975, $A 31,245$

(40) Sheldrick, G. M. SHELXS86: Program for crystal structure determination. Univ. of Göttingen, Federal Republic of Germany, 1986.

(41) Sheldrick, G. M. SHELX76: Program for crystal structure determination. Univ, of Cambridge, England, 1976. parameter: $F_{\mathrm{c}}{ }^{\prime}=F_{\mathrm{c}}\left(1-X F^{2} /(\sin \theta)\right)$, with $X=1.87(10) \times 10^{-6}$ and 1.54 (4) $\times 10^{-6}$ for 5 and 7 , respectively. Weights were introduced in the final refinement cycles. Neutral-atomic scattering factors were taken from Cromer and Mann; ${ }^{42}$ anomalous-dispersion corrections from Cromer and Liberman. ${ }^{43}$ Geometric calculations and illustrations were performed with PLATON $^{44}$ on a MicroVax-II cluster and a DECstation 5000. Final atomic coordinates and equivalent isotropic thermal parameters of the non-hydrogen atoms for $2,4,5$, and 7 are given in Tables VII-X, respectively.

Acknowledgment. We thank the Innovation Oriented Research Program on Catalysis for financial support (to P.L.A.). The Netherlands Foundation for Chemical Research (SON) and the Netherlands Organization for Scientific Research (NWO) are thanked for financial support (to A.L.S.). X-ray data for 2 and 4 were kindly collected by A. J. M. Duisenberg.

Supplementary Material Available: Derivation of the Scatchard equation (text and a figure) for a compound with two binding sites and tables of fractional cocrdinates of the hydrogen atoms, anisotropic thermal parameters, and bond distances and angles of the non-hydrogen and hydrogen atoms of 2,4 , and 7 (15 pages). Ordering information is given on any current masthead page.

\section{OM920367F}

(42) Cromer, D. T.; Mann, J. B. Acta Crystallogr. 1968, A24, 321

(43) Cromer, D. T.; Liberman, D. J. Chem. Phys, 1970, 53, 1891.

(44) Spek, A. L. Acta Crystallogr. 1990, A46, C34.

\title{
Nickel-Catalyzed Reactions of 3,4-Benzo-1,1,2,2-tetraethyl-1,2-disilacyclobutene with Aromatic Compounds
}

\author{
Mitsuo Ishikawa," Shougo Okazaki, Akinobu Naka, and Hiromu Sakamoto \\ Department of Applied Chemistry, Faculty of Engineering, Hiroshima University, Higashi-Hiroshima 724, Japan
}

Received April 27, 1992

The reaction of 3,4-benzo-1,1,2,2-tetraethyl-1,2-disilacyclobutene (1) with benzene in the presence of $\mathrm{Ni}\left(\mathrm{PEt}_{3}\right)_{4}$ gave 1-(diethylphenylsilyl)-2-(diethylsilyl)benzene (4a) in high yield. Similar reaction of 1 with toluene gave 1-[diethyl(3-methylphenyl)silyl]- and 1-[diethyl(4-methylphenyl)silyl]-2-(diethylsilyl)benzene $(5 a, b)$. The reaction of 1 with isopropylbenzene also produced the corresponding two regioisomers. With $m$-xylene, 1 afforded 1-[diethyl(3,5-dimethylphenyl)silyl]- and 1-[diethyl(2,4-dimethylphenyl)silyl]-2(diethylsilyl)benzene, while the reaction of 1 with $p$-xylene gave 1-[diethyl(2,5-dimethylphenyl)silyl]-2(diethylsilyl)benzene as a main product, in addition to 1-[diethyl(4-methylbenzyl)silyl]-2-(diethylsilyl)benzene as a minor product. Similar reaction of 1 with mesitylene gave 1-[diethyl(3,5-dimethylbenzyl)silyl]-2(diethylsilyl)benzene. The nickel-catalyzed reaction of 1 with a 1:1 mixture of benzene and toluene afforded $\mathbf{4 a}, 5 \mathbf{a}$, and $\mathbf{5 b}$ in 56,22 , and $9 \%$ yields, while, with a $1: 1$ mixture of benzene and mesitylene, $4 \mathbf{a}$ was produced as the sole product.

\section{Introduction}

Although considerable attention has been devoted to investigations of the strained small-ring compounds involving a silicon-silicon bond in the ring system, ${ }^{1,2}$ much less interest has been shown in the chemistry of benzodisilacyclobutenes. ${ }^{3}$ To our knowledge, only one paper

(1) Brook, A. G. The Chemistry of Organic Silicon Compounds. Part 2; Patai, S., Rappoport, Z., Eds.; Wiley: New York, 1989; Chapter 15. (2) Raabe, G.; Michl, J. Reference 1, Chapter 17.

(3) For 1,2-disilacyclobutenes, see refs, 4-6, and for 2,3-benzo-1-silacyclobutenes, see refs 7 and 8 . concerning the synthesis of 3,4-benzo-1,1,2,2-tetramethyl-1,2-disilacyclobutene and its ring-opening polymerization has been reported to date. ${ }^{9}$

(4) Barton, T.; Kilgour, J. A. J. Am. Chem. Soc. 1976, 98, 7746.

(5) Sakurai, H.; Kobayashi, H.; Nakadaira, Y. J. Organomet. Chem. $1978,162, \mathrm{C} 43$.

(6) Ishikawa, M.; Sugisawa, H.; Kumada, M.; Kawakami, H.; Yamabe, T. Organometallics 1983, 2, 974.

(7) Okazaki, R.; Kang, K.-T.; Inamoto, N. Tetrahedron Lett. 1981, 22, 235 761. 